\title{
AA5083 (Al-Mg) plates produced by wire-and-arc additive manufacturing: effect of specimen orientation on microstructure and tensile properties
}

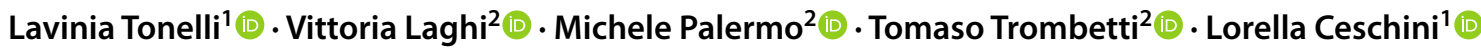

Received: 9 September 2020 / Accepted: 19 April 2021 / Published online: 6 May 2021

(c) The Author(s) 2021

\begin{abstract}
Among various additive manufacturing (AM) technologies, wire-and-arc additive manufacturing (WAAM) is one of the most suitable for the production of large-scale metallic components, also suggesting possible applications in the construction field. Several research activities have been devoted to the WAAM of steels and titanium alloys and, recently, the application of WAAM to aluminum alloys has also been explored. This paper presents the microstructural and mechanical characterization of WAAM plates produced using a commercial ER 5183 aluminum welding wire. The aim is to evaluate the possible anisotropic behavior under tensile stress of planar elements, considering three different extraction directions in relation to the deposition layer: longitudinal (L), transversal (T) and diagonal (D). Compositional, morphological, microstructural and fractographic analyses were carried out to relate the specific microstructural features induced by WAAM to the tensile properties. An anisotropic behavior was found in regard to the specimen orientation, with the lowest strength and ductility found on $\mathrm{T}$ specimens. Reasoning to this was found in the presence of microstructural discontinuities unfavorably oriented with regard to the tensile direction. The results of tensile tests also highlighted an overall good mechanical behavior, comparable to that of conventional AA5083-O sheets, suggesting future use in the realization of very complex geometries and optimized shapes for lightweight structural applications.
\end{abstract}

Keywords Directed energy deposition · Wire-and-arc additive manufacturing $\cdot$ Aluminum alloys $\cdot$ Tensile testing · Microstructure

\section{Introduction}

Among the various additive manufacturing (AM) techniques, one of the most suitable for producing large metal components for structural engineering purposes is the socalled wire-and-arc additive manufacturing (WAAM) [1]. WAAM is a direct energy deposition (DED) technology that derives from conventional welding processes and, as for the latter, it can be classified as gas metal arc welding (GMAW), gas tungsten arc welding (GTAW) and plasma arc welding

Lavinia Tonelli

lavinia.tonelli2@unibo.it

1 Department of Industrial Engineering (DIN), University of Bologna, Viale del Risorgimento, 4, 40136 Bologna, Italy

2 Department of Civil, Chemical, Environmental and Materials Engineering (DICAM), University of Bologna, Viale del Risorgimento, 2, 40136 Bologna, Italy
(PAW), according to the heat source [2]. The main advantage of this AM-based technology lies upon the possibility to realize complex-shaped large-scale structural elements, with high deposition rates and still ensuring lower overall production costs, including that of feedstock material, if compared to other additively manufactured techniques for metals [3-5]. Furthermore, a wide range of materials can be processed by WAAM, such as steels [6-8], titanium $[9,10]$ and shape memory alloys [11-13]. Additive manufacturing of aluminum alloys has been extensively investigated considering AM process based on the fusion of a powder bed [14-16]; however, the application of WAAM technologies was also recently investigated. An extensive research effort has been devoted to GMAW and GTAW-based WAAM processes for aluminum alloys [17], also focusing on wrought $\mathrm{Al}-\mathrm{Mg}$ alloys of the 5000 series [18-23]. The 5000 series of aluminum alloys offers an excellent combination of corrosion resistance, strength, toughness, weldability, and for 
these reasons, it is widely used in shipbuilding, automotive, aerospace and industrial sectors.

Aluminum alloys are also highly appreciated in the building sector for their high strength-to-weight ratio, very long in-service life, low maintenance, and contribution to the energy performance of buildings [24]. The low elastic modulus could be a main limit in the use of $\mathrm{Al}$ alloys in building, but it is well known that the global stiffness of structural elements can be improved by a proper design of cross sections characterized by high moment of inertia. This can be achieved by the use of complex-shaped extrudates, often made of the 6000 aluminum alloys series since the use of the 5000 series alloys is limited by their low extrudability. In this view, the WAAM process would help realizing optimized cross-section members of the 5000 series to guarantee a superior stiffness with a minimum amount of material, also gaining the advantage of the superior corrosion resistance of this series by comparison to the 6000 one [25].

Up to date, the research work on WAAM of 5000 series alloys (5083, 5183, 5087, 5356) has been focused on: (1) tensile behavior $[18,19,21,26]$; (2) microstructural defects induced by the process [17-20]; and (3) possible anisotropic mechanical behavior induced by the process $[18,20,21,26]$.

From literature review, WAAM components made of the 5000 series alloys generally present quite evident microstructural defects and, in particular, large amount of internal gas porosity [17-20]. Indeed, gas porosity is considered one of the major issues concerning WAAM of aluminum alloys [27] and it is mainly ascribable to the large hydrogen solubility in molten aluminum. However, also the vaporization of low-melting alloy elements, such as $\mathrm{Mg}$, should be taken into consideration [28-30]. The problem of gas entrapment can be mitigated by controlling the heat input during the process, for example by adopting the cold metal transfer (CMT) process, a variation of GMAW able to reduce heat input and, thus, hydrogen solubility. However, CMT is a patented process and requires specific equipment. Furthermore, preliminary results of the CMT applied to the Al-Mg alloys also show a significant porosity content [18, 21].

Regarding tensile properties, when considering two different directions of samples extraction (i.e., parallel and perpendicular) from WAAM plates, with regard to the deposition layer, literature results report an almost isotropic tensile behavior [18, 26, 31]. On the contrary, tests carried out on stainless steel WAAM plates show a highly anisotropic behavior [32-34]. Moreover, to the best of the authors knowledge, for $\mathrm{Al}$ alloys of the 5000 series, there are no data currently available on the tensile behavior of specimens extracted at $45^{\circ}$ with regard to the deposition layer.

Based on the above, the focus of the present study is to investigate the influence of the deposition layer orientation on the tensile properties of AA5183 aluminum plates produced by GMAW-WAAM. To highlight a possible anisotropic behavior, tensile tests have been carried out on specimens extracted from WAAM plates considering three orientations, being perpendicular $\left(90^{\circ}\right)$, parallel $\left(0^{\circ}\right)$ and diagonal $\left(45^{\circ}\right)$ to the deposition layer. Results of tensile tests are correlated with the results of extensive microstructural and fractographical analyses, aimed at relating the new production process to the specific induced microstructural features and consequently to the final mechanical properties and failure mechanisms. In addition, since surface quality is one of the major drawbacks of additively manufactured components, especially produced by WAAM, profilometric and morphological characterization of the as-printed surfaces was carried out. In fact, proper characterization of the inherent surface roughness of the printed outcomes is crucial to define the as-built mechanical properties [33, 35] for large-scale production and in situ fabrication (for which machining is unfeasible) as well as for their fatigue and corrosion behavior.

\section{Experimental procedure}

\subsection{Material and process}

The WAAM aluminum plates $\left(380 \times 380 \times 4 \mathrm{~mm}^{3}\right)$ analyzed in the present work were manufactured and supplied by the Dutch company MX3D [36]. The commercially available aluminum AlMg4.5Mn0.7 welding wire (ER 5183 according to AWS A5.10 designation [37]) supplied by Oerlikon [38] was used as feedstock material. GMAW-based process with a standard pulse signal was adopted to build the aluminum plates and the main process parameters are reported in Table 1. According to the scheme in Fig. 1, plates were built in the vertical $(z)$ direction by overlapping individual layers of metallic material.

Table 1 Process parameters used for WAAM deposition (courtesy of MX3D [36])

\begin{tabular}{lll}
\hline Process parameters & Details & Value \\
\hline Deposition power & Current & $30-50 \mathrm{~A}$ \\
& Arc voltage & $14-15 \mathrm{~V}$ \\
Speed & Welding speed & $12-15 \mathrm{~mm} / \mathrm{s}$ \\
& Wire feed rate & $2-3 \mathrm{~m} / \mathrm{min}$ \\
& Deposition rate & $0.5-2 \mathrm{~kg} / \mathrm{h}$ \\
Distance and angle & Layer height & $0.5-2 \mathrm{~mm}$ \\
& Electrode to layer angle & $90^{\circ}$ \\
Wire & Wire grade & ER 5183 \\
& Wire diameter & $1.2 \mathrm{~mm}$ \\
Shield gas & Shield gas type & $100 \% \mathrm{Ar}$ \\
& Shield gas flow rate & $10-20 \mathrm{~L} / \mathrm{min}$ \\
\hline
\end{tabular}




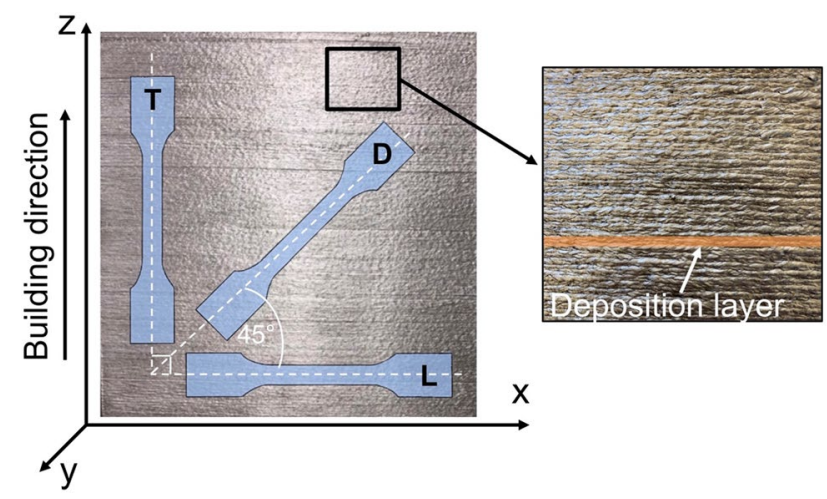

Fig. 1 A representative WAAM aluminum plate $\left(380 \times 380 \times 4 \mathrm{~mm}^{3}\right)$ and schematic representation of samples extraction directions according to the building direction ( $z$ axis) and deposition layer ( $x$ axis); in the inset a detail of as-built surface were the deposition layer is highlighted

Chemical composition of WAAM plates was checked by means of quantitative analysis carried out by Glow Discharge Optical Emission Spectroscopy (GDOES, Spectruma Analytik GDA-650).

\subsection{Mechanical tests}

Mechanical characterization of WAAM plates consisted of tensile and hardness tests. Flat dog-bone tensile specimens were machined from the AM plates considering three main directions, with regard to the deposition layer, as represented in Fig. 1: longitudinal (L), transversal (T) and diagonal (D) being parallel, perpendicular and inclined at $45^{\circ}$ to the layer, respectively. For each plate, all three directions were tested, so the results of the mechanical characterization represented the overall mechanical performance of the WAAM plates. Tensile tests, performed at room temperature, were carried out on flat specimens, whose geometry and dimensions were chosen according to ISO 6892-1 [39] (gauge length of $160 \mathrm{~mm}$, gauge width of $20 \mathrm{~mm}$ and nominal thickness of $4 \mathrm{~mm}$ according to ASTM E8/E8M-16a standard [40]) maintaining the as-built surface roughness of the WAAM plates (Fig. 2).

The tensile tests were performed according to ISO 6892-1 [39] on a Metrocom universal testing machine of $500 \mathrm{kN}$ load capacity under displacement control with a loading rate of $2 \mathrm{MPa} / \mathrm{s}$. Strain up to the yield point was measured by a linear variable displacement transducer (LVDT) of $50 \mathrm{~mm}$ gauge length (Fig. 3).

Four specimens for each extraction direction (L, T and D) were tested. Before testing, gauge length dimensions of each specimen were measured by means of digital caliper. Given the inherent surface roughness of the specimens (Fig. 1) due to the printing process, the values of crosssectional area and thickness used to process the experimental results were taken from volume equivalency, by means of the Archimedes' principle, according to previous literature work on as-built WAAM specimens [32, 33]. The volume-equivalent average values of thickness $t$ and cross-sectional area $A$ of the gauge length were found equal to $4.10 \mathrm{~mm}$ and $81.45 \mathrm{~mm}^{2}$, respectively. The coefficient of variation of both thickness and cross-sectional area (based on the measures taken for the 12 specimens) is 0.02 . Density of WAAM samples was determined by means of volume-based measures taken with a hydraulic scale according to the Archimedes' principle, which resulted to be on average equal to $2640 \mathrm{~kg} / \mathrm{m}^{3}$, slightly below the typical value of conventionally manufactured

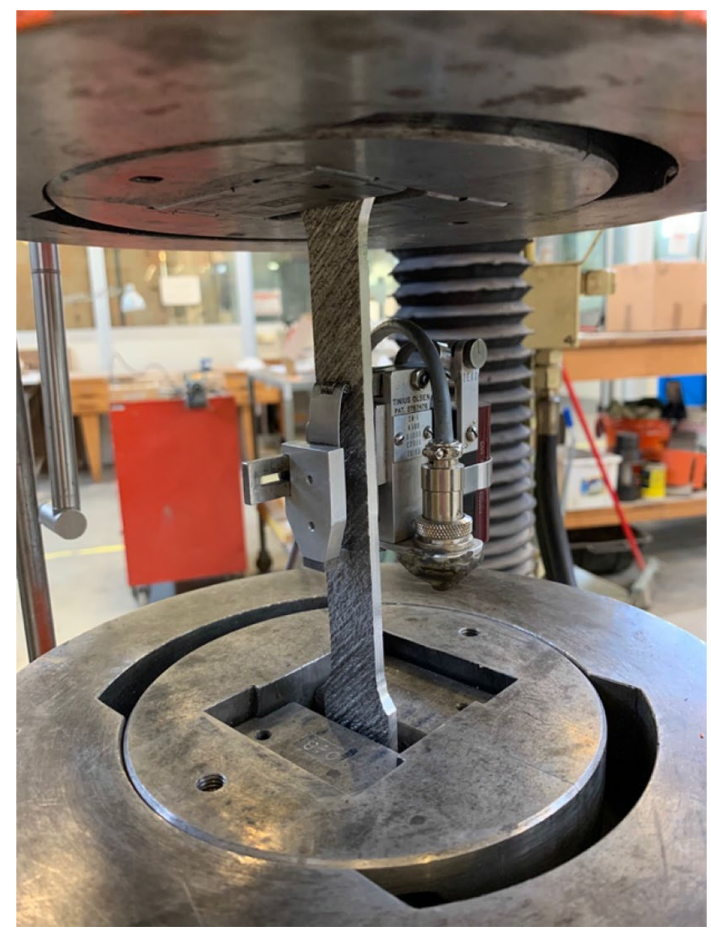

Fig. 3 Tensile test set-up
Fig. 2 Representative flat dogbone specimen for tensile test (160 mm gauge length, $20 \mathrm{~mm}$ gauge width, $4 \mathrm{~mm}$ nominal thickness, according to ASTM E8/E8M-16a standard [37])

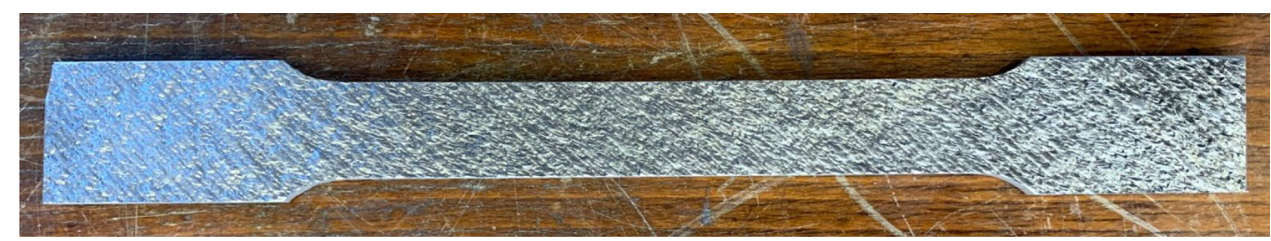


aluminum alloys for structural applications $\left(2700 \mathrm{~kg} / \mathrm{m}^{3}\right.$, as suggested also in EN1999 [41]). The result, as will be later discussed, is related to the high porosity content evidenced by microstructural and fractographic analyses.

Elastic modulus $(E)$, yielding stress (calculated as $0.2 \%$ proof stress) (YS), ultimate tensile strength (UTS) and elongation to failure $\left(A_{\%}\right)$ were evaluated from the engineering stress-strain curves. To evaluate the hardness of the WAAM plates, $\mathrm{HV}_{1}$ Vickers tests $(1 \mathrm{~kg}$ load, $15 \mathrm{~s}$ dwell time) were carried out on metallographic samples extracted from the grip region of tensile specimens and subsequently subjected to grinding and polishing procedures.

\subsection{Samples characterization}

Surface topography of WAAM plates was analyzed by means of a 3D Digital Microscope (Hirox KH-7700) with the aim of characterizing morphological features peculiar of the aluminum alloys WAAM plates. Waviness and roughness profiles, as well as $R_{a}$ and $R_{z}$ values, were evaluated according to the EN ISO 4287 standard [42] by means of a stylus profilometer (Hommelwerke T2000, $5 \mu \mathrm{m}$ tip radius).

Phase composition was determined by X-ray diffraction (XRD, PANalytical Expert PRO with Xcelerator detector) operating at $40 \mathrm{kV}$ and $40 \mathrm{~mA}$. For XRD analysis, $\mathrm{Cu}-\mathrm{K} \alpha$ $(\lambda=0.15406 \mathrm{~nm})$ was used as radiation source and scans were carried out from $20^{\circ}$ to $90^{\circ}(\theta-2 \theta)$, with a $0.01^{\circ}$ step size and a 10-s dwell time.

A comprehensive macro- and microstructural characterization was performed via Optical Microscopy (OM) and Field Emission Gun Scanning Electron Microscopy equipped with an Energy-Dispersive X-ray Spectroscope (FEG-SEM EDS), using both secondary and back-scattered electrons. According to the scheme reported in Fig. 4, samples for microstructural analyses were extracted from grip regions of $\mathrm{L}, \mathrm{D}$ and $\mathrm{T}$ tensile specimens and the three principal cross sections (lying on $x-z, x-y$ and $z-y$ planes) were considered.

Standard grinding and polishing procedures (ASTM E3 [43]) were used for preparing metallographic samples and, to reveal specific microstructural features, chemical etching was carried out via $30 \mathrm{~s}$ immersion in the Keller's reagent (2.5 $\mathrm{mL} \mathrm{HNO}_{3}, 1.5 \mathrm{~mL} \mathrm{HCl}, 1.0 \mathrm{~mL} \mathrm{HF}$ and $95 \mathrm{~mL}$ distilled water [44]).

Fracture surfaces of the tensile specimens were first inspected by 3D Digital microscopy and then by FEG-SEM EDS microscopy, for both a general and more detailed characterization. To investigate the crack path, samples extracted close to the fracture surfaces were also subjected to metallographic preparation, as described above, and then analyzed by OM and FEG-SEM.

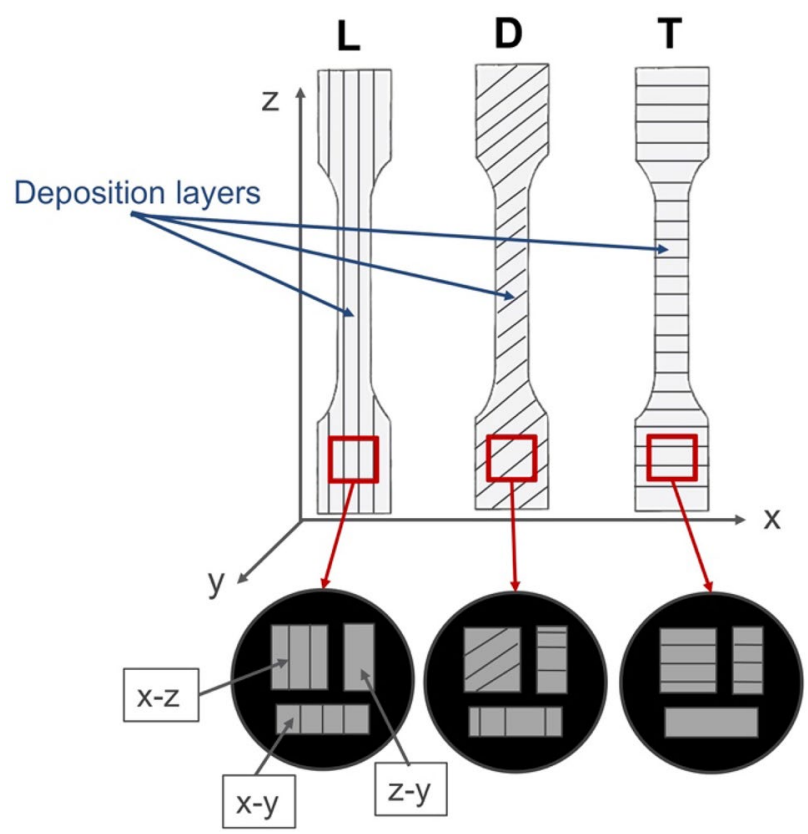

Fig. 4 Samples for microstructural analyses: schematic representation of samples extraction directions from $\mathrm{L}, \mathrm{D}$ and $\mathrm{T}$ tensile specimens

\section{Results and discussion}

\subsection{Chemical and morphological characterization}

The results of chemical composition analysis, carried out by GD-OES, are reported in Table 2 and compared to the nominal composition of the ER5183 feedstock wire, as provided by the supplier [38], and to the nominal composition of AA5083 alloy [25], of which the ER5183 wire is the common filler material. Results show that, by comparison to the feedstock wire, WAAM plates exhibited a higher content of the main alloy element $(\mathrm{Mg})$ and a lower presence of $\mathrm{Mn}$; however, these values fall within the range of AA5083. It is worth noticing also that no trace of $\mathrm{Si}$ or $\mathrm{Cu}$, nominally present in the wire and in the nominal composition of the AA5083 alloy, was detected on samples extracted from the as-built WAAM plates.

As concerning morphological characterization, it can be inferred that the surface of WAAM plates is characterized by a high roughness and a marked waviness, inherent of the process itself that consists of subsequent deposition of thick (1-2 $\mathrm{mm}$ ) layers of molten material [45]. Evidence can be found in the representative waviness profile measured by a stylus profilometer along the building direction ( $z$ axis) on the surface of WAAM plates (Fig. 5a), where it is possible to recognize a cyclic repetition of peaks and valleys, consistent with the layer deposition thickness $(0.5-2 \mathrm{~mm}$, Table 1$)$, being the maximum distance between the highest peak and the lowest valley 
Table 2 Chemical composition of WAAM aluminum plates (mean value and standard deviation) measured by GD-OES, compared to the nominal composition of the feedstock wire ER5183 provided by the supplier and AA5083 alloy [25]

\begin{tabular}{llllllllll}
\hline \multicolumn{7}{c}{ Elements (wt\%) } & \multicolumn{7}{l}{} & & & \\
\cline { 2 - 9 } & $\mathrm{Al}$ & $\mathrm{Mg}$ & $\mathrm{Mn}$ & $\mathrm{Fe}$ & $\mathrm{Zn}$ & $\mathrm{Ti}$ & $\mathrm{Cr}$ & $\mathrm{Si}$ & $\mathrm{Cu}$ \\
\hline WAAM plates & & & & & & & & \\
Mean & Bal & 4.876 & 0.614 & 0.097 & 0.032 & 0.086 & 0.042 & - & - \\
SD & & \pm 0.047 & \pm 0.013 & \pm 0.003 & \pm 0.002 & \pm 0.003 & \pm 0.001 & & \\
Wire & Bal & 4.5 & 0.8 & 0.1 & - & 0.1 & 0.1 & 0.3 & 0.1 \\
AA5083 & Bal & $4.0-4.9$ & $0.4-1.0$ & 0.4 & 0.25 & 0.15 & $0.05-0.25$ & 0.4 & 0.1 \\
\hline
\end{tabular}

Where a specific range is not reported, value has to be considered as maximum admissible content
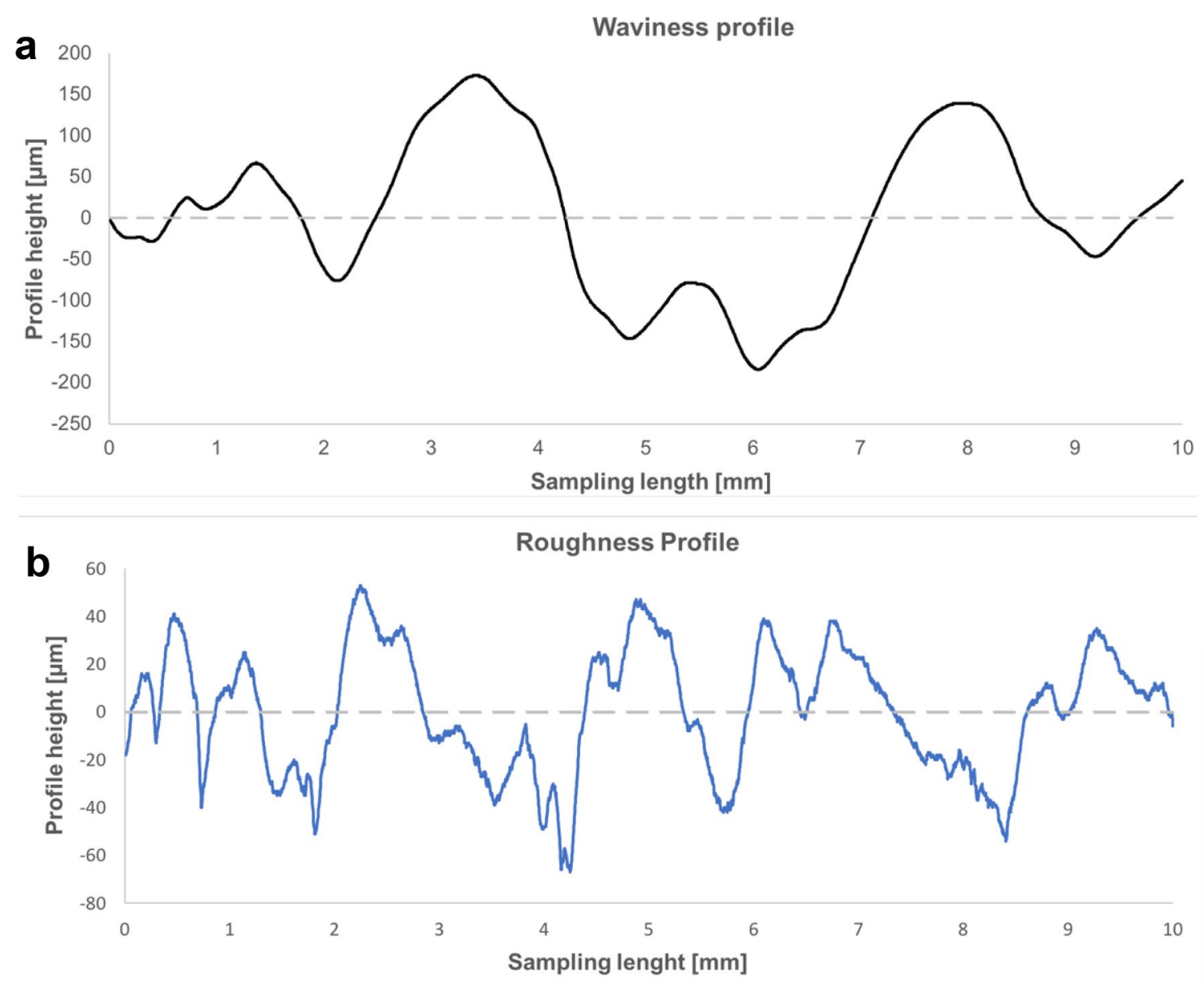

Fig. 5 Profilometric analyses of WAAM plates surface: a representative waviness profile along building direction ( $z$ axis), b corresponding roughness profile

(total height of waviness profile) equal to $357 \mu \mathrm{m}$. The corresponding roughness profile is reported in Fig. 5b and reveals a poor surface finishing, characterized by $R_{a}=21 \mu \mathrm{m}$ and $R_{z}=94 \mu \mathrm{m}$. The high surface roughness can be ascribable to the deposition process, consisting of the subsequent formation of melt pools to realize the single layer, as highlighted by 3D digital micrographs reported in Fig. 6. Figure 6a shows the typical surface of WAAM plates, where both the deposited layers (whose boundaries are highlighted by yellow dashed lines) and melt pools (highlighted by red dashed lines) can be recognized. In some cases, typical defects of conventional welding process, also reported for WAAM components, were detected on plates surfaces ( $x-z$ plane) $[44,45]$. For example, Fig. 6b shows a collapsed melt pool, while spatters, consisting of metal droplets ejected from the liquid pool and then solidified in spherical shape, can be seen in Fig. 6c. 

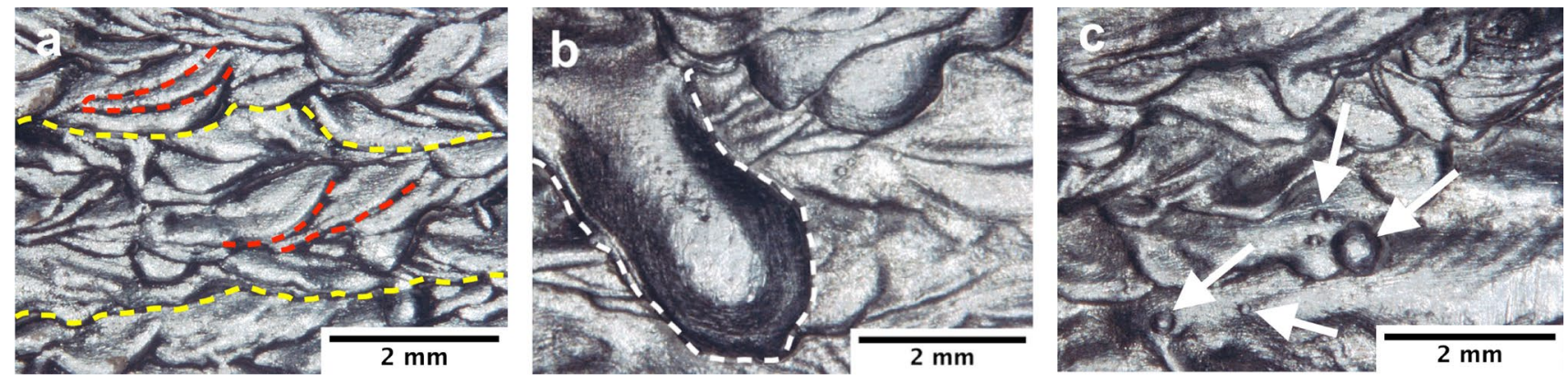

Fig. 6 3D digital micrographs of WAAM plates surface ( $x-z$ plane): a typical surface where dashed yellow lines highlight deposition layers boundaries while red ones highlight melt pools boundaries, b

\subsection{Phase composition}

The results of X-ray diffraction analyses performed on L, D and $T$ samples are reported in Fig. 7. In the general view of spectra (Fig. 7a), only the $\alpha-\mathrm{Al}$ phase can be appreciated. By focusing on the low intensities, in the range of $2 \theta=20^{\circ}-60^{\circ}$ (Fig. 7b), for all three directions, few small peaks can be recognized, that can be attributed to second phases, i.e., intermetallic compounds. In $\mathrm{Al}-\mathrm{Mg}-\mathrm{Mn}$ alloys, main intermetallic compounds are Mg-rich and Fe-rich [46-48] such as $\mathrm{Al}_{3} \mathrm{Mg}_{2}, \mathrm{Al}_{5} \mathrm{Mg}_{8}$, and $\mathrm{Al}_{6}(\mathrm{Fe}, \mathrm{Mn})$. Similar spectra were presented by [49], who studied the effect of Fe and Mn addition to the $\mathrm{Al}-5 \mathrm{Mg}-\mathrm{Mn}$ alloy solidified in near-rapid cooling conditions, and by [18] who investigated the AA5183 alloy processed by CMT WAAM. They evidenced the presence of $\mathrm{Al}_{6}(\mathrm{Fe}, \mathrm{Mn})$ and $\mathrm{Al}_{5} \mathrm{Mg}_{8}$ with peaks located in the range $2 \theta=35^{\circ}-43^{\circ}$ thus, as also supported by FEG-SEM analyses later discussed, low intensity peaks in Fig. $7 \mathrm{~b}$ can be reasonably attributed to these intermetallic compounds.

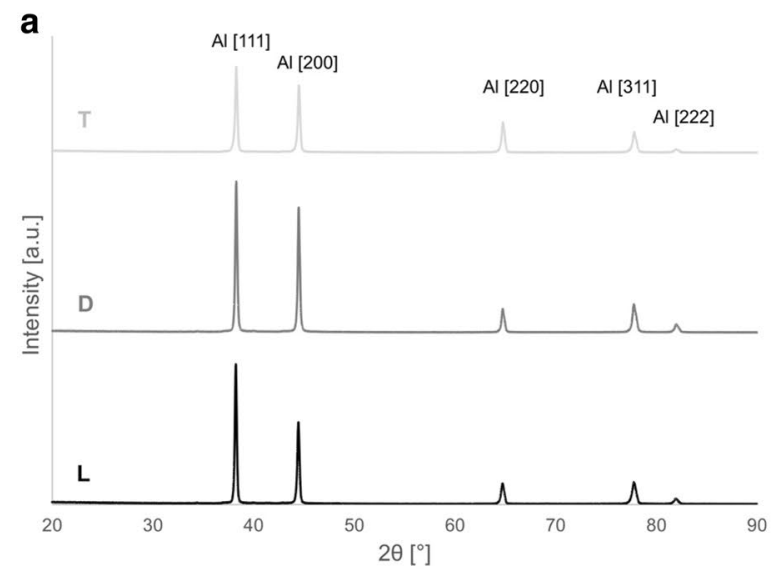

collapsed melt pool underlined by white dashed line, $\mathbf{c}$ spatters, indicated by white arrows

\subsection{Microstructural characterization}

Microstructure of L, D and T samples was first studied by light microscopy (OM) along three main directions, in accordance with Fig. 4, thus allowing assembling the threedimensional reconstructions shown in Fig. 8. As it can be noticed from this figure, microstructural features such as layer boundaries (yellow dashed lines) and melt pool boundaries (red dashed lines) were differently oriented with reference to the tensile test direction (black arrows) in L, D and $\mathrm{T}$ samples and this should lead to a different mechanical response. Extensive macro- (greater than $100 \mu \mathrm{m}$ ) and micro-porosity (of about a few of tens of micrometers) were detected in all samples, being the latter one mainly located in correspondence of interlayer regions and melt pool borders, as showed in Fig. 9a. Porosity located in the region adjacent to layer boundaries was also found by other researchers in Al-Mg alloys processed by WAAM [18-21,31] and it is considered one of the major issues in processing aluminum

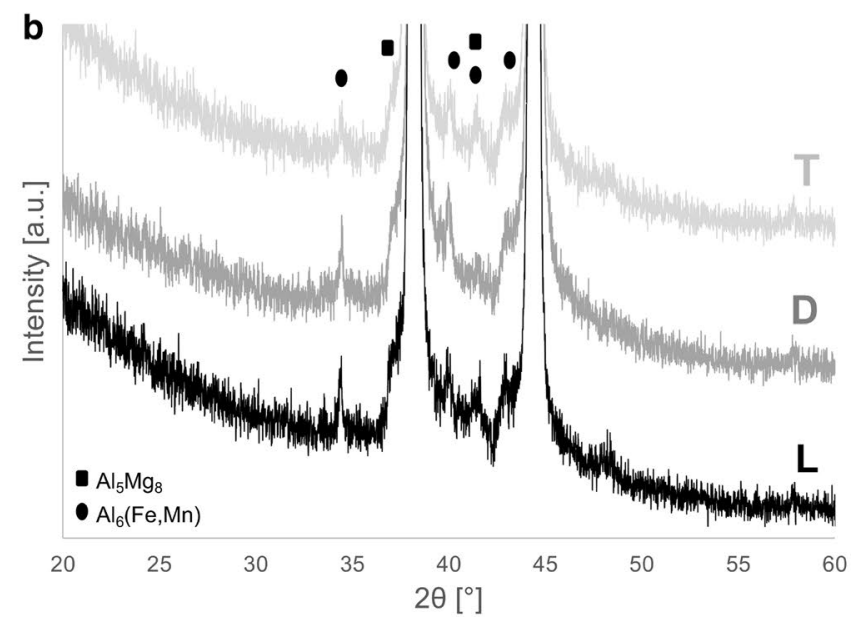

Fig. 7 XRD analysis: a whole spectra and $\mathbf{b}$ detail of low peaks in the $20^{\circ}-60^{\circ}$ portion for longitudinal (L), diagonal (D) and transverse (T) samples 


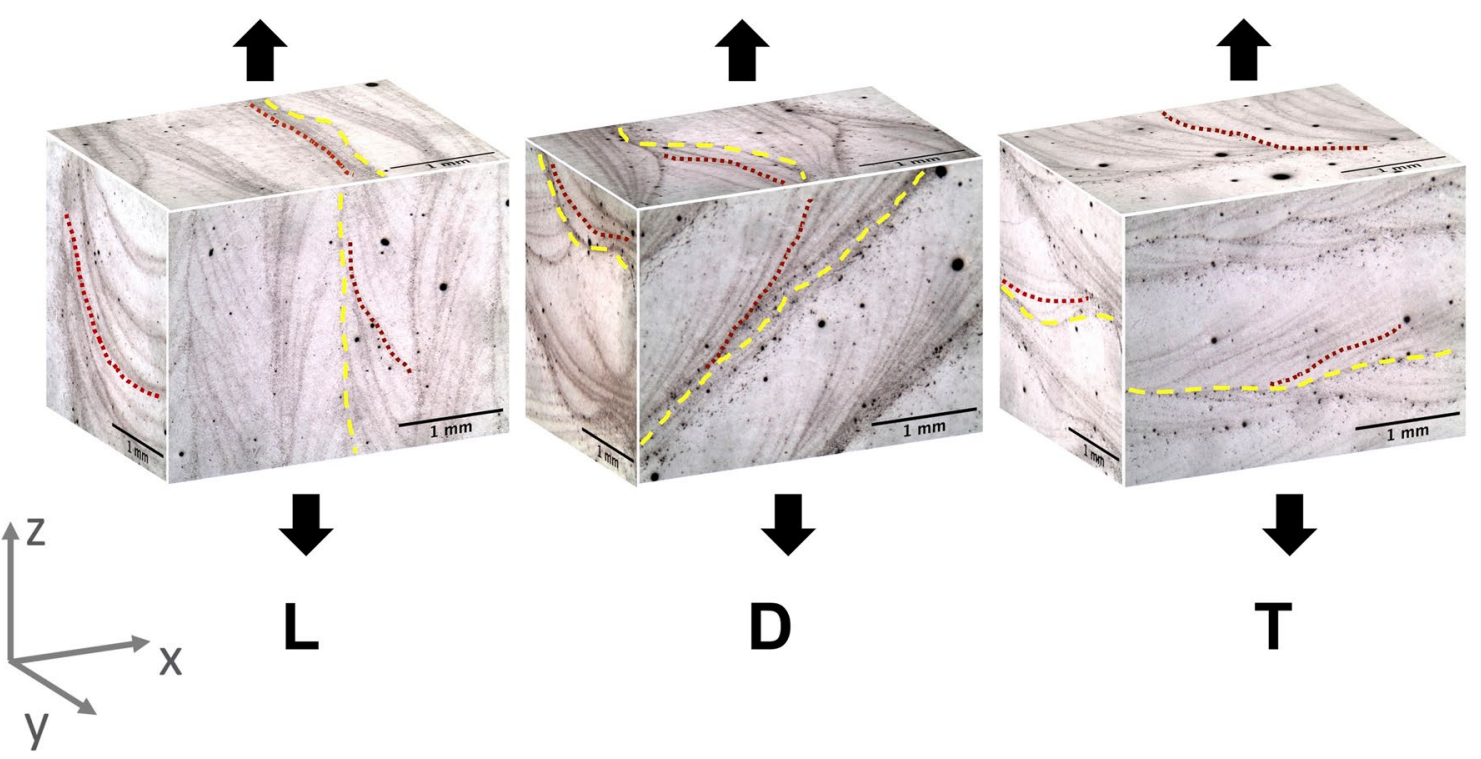

Fig. 8 3D microstructural reconstructions by optical micrographs of longitudinal (L), diagonal (D) and transverse (T) samples. Black arrows indicate tensile direction, yellow dashed lines highlight layer boundaries and red dashed lines highlight melt pool boundaries

Fig. 9 Micrographs of a representative samples showing: a porosity and cracks in the interlayer region (yellow dashed line identifies layer boundary, red dashed line indicates a melt pool boundary), b detail of cracks
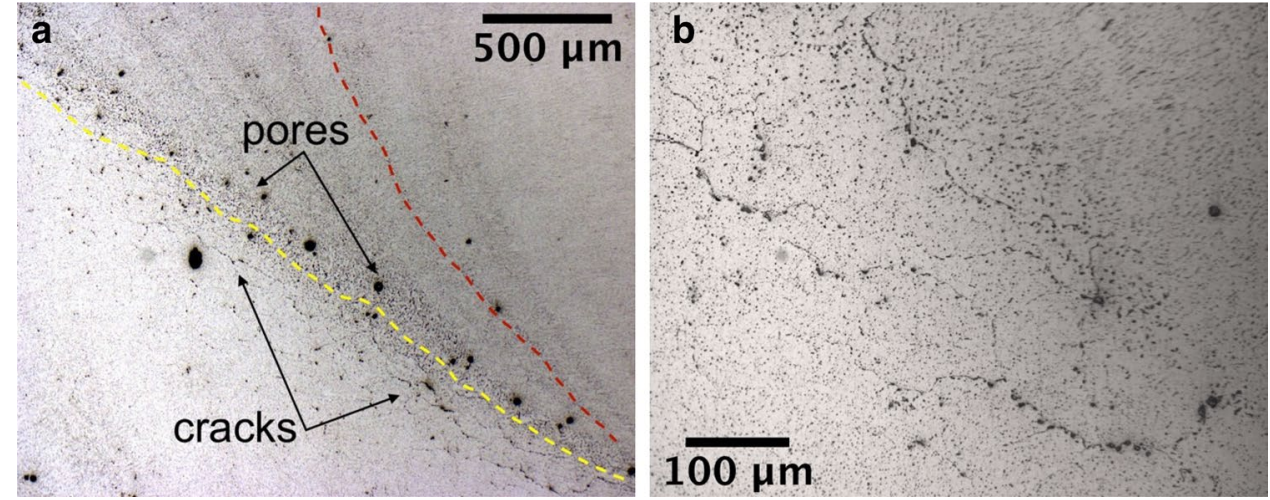

alloys with this technology $[2,27]$. Such porosities are commonly spherical in shape, as in the present study, thus suggesting gas entrapment, ascribable to the shielding gas and especially to the hydrogen content, whose solubility in solid aluminum is much smaller than that in the molten state $[27,50]$. The hydrogen content is probably derived from surface contamination of melt pool or feedstock wire, such as moisture that reacted with molten aluminum during the process [2]. Consequently, the phenomena can be reduced by a careful storage and handling of the feedstock material and protection of melt region. Microcracks in the interlayer region were also evidenced (Fig. 9b), mainly located in the area subjected to re-heating by the deposition of the subsequent layer. Intergranular cracks were already reported in the literature by Horgar et al. [20] for the WAAM processed AA5183 and they were attributed to the hot cracking phenomenon. It is well known that hot cracking is mainly related to the alloy composition that indirectly refers to the amount of eutectic present at solidification and, for this reason, this is the main welding problem of the AA5083 alloy, not readily eliminated by simple change in welding procedures [51, 52]. Some studies [53, 54] evidenced the positive effect of titanium (Ti)-boron (B), scandium ( $\mathrm{Sc}$ ), erbium (Er) and zirconium ( $\mathrm{Zr}$ ) additions on mitigating the hot cracking tendency, due to the induced grain refinement. It should be also mentioned that WAAM, even if it is not the $\mathrm{AM}$ process with the highest cooling rate, yet results in a very fine microstructure; thus, microcracks are presumably mainly related to porosity content rather than hot cracking. As shown in Fig. 9b, in fact, cracks tend to connect microporosities present in the interlayer region.

The analysis at the optical microscope revealed the presence of two main phases: a light one, being the primary $\alpha$-Al phase, and a dark one corresponding to secondary phases, such as intermetallic compounds (Fig. 10a). Second phases were already detected by XRD analyses (Fig. 7) and 
Fig. 10 Microstructural analyses: a optical micrographs of an interlayer region, b FEG-SEM micrographs showing the two different types of intermetallic compounds (indicated by white arrows), $\mathbf{c}$ and $\mathbf{d}$ FEG-SEM EDS analysis of intermetallic compounds
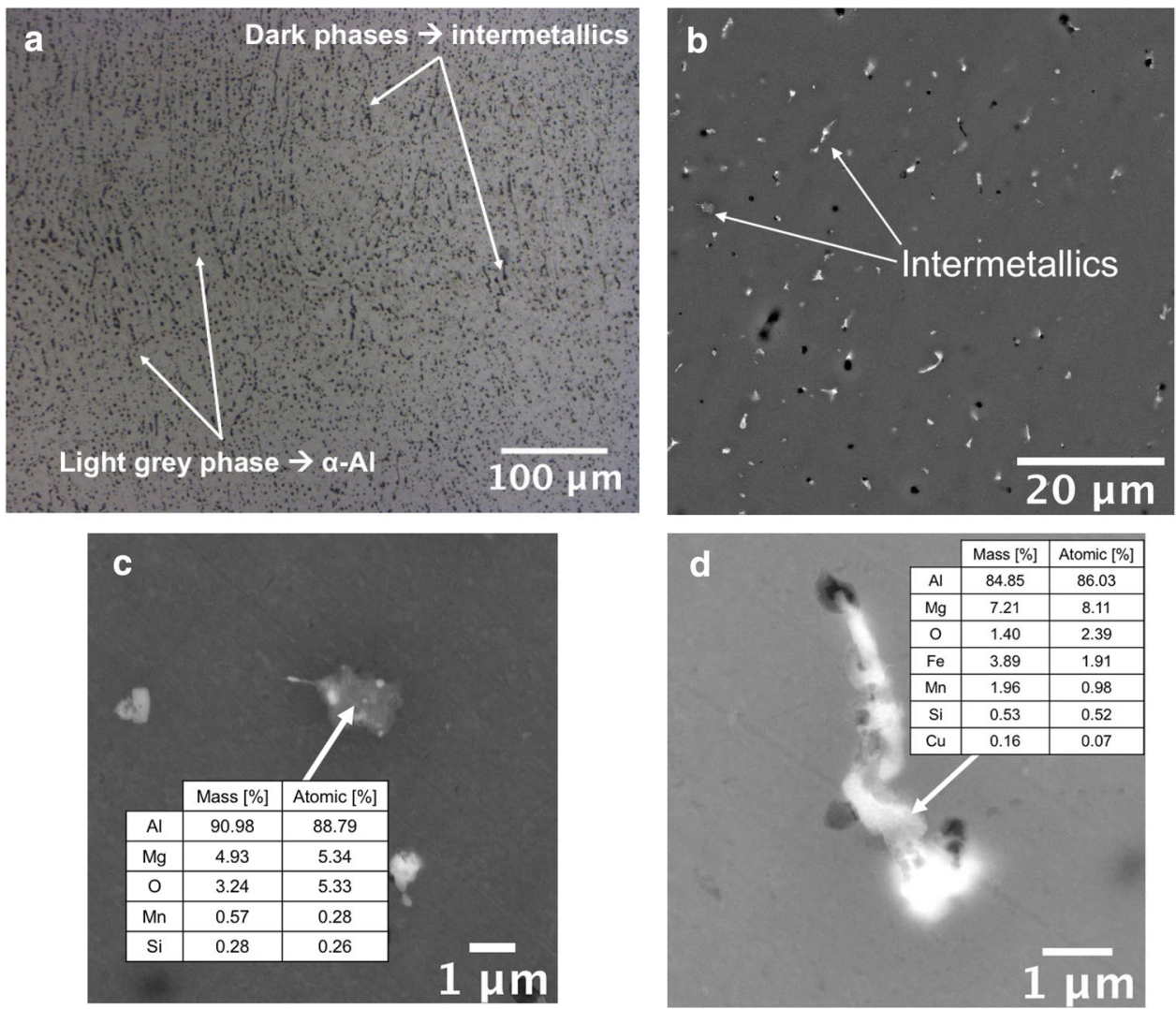

attributed to $\mathrm{Fe}$ - and $\mathrm{Mg}$-rich intermetallic phases. In the reason of the high cooling rate that the material experiences during WAAM process $[45,55]$, these secondary phases were extremely fine [49] and, in addition, they were uniformly distributed in the Al matrix, as already observed by [18]. FEG-SEM analyses (Fig. 10b) evidenced two different types of intermetallic compounds, that have been further investigated by EDS spectroscopy (Fig. 10c, d). In accordance with XRD results, gray equiaxed particles (Fig. 10c) mainly contain $\mathrm{Al}, \mathrm{Mg}$ and $\mathrm{Mn}$ and, thus, were consistent with the $\mathrm{Al}_{5} \mathrm{Mg}_{8}$ phase, while bright vermicular particles (Fig. 10d), in the reason of the presence of Fe, could be identified as $\mathrm{Al}_{6}(\mathrm{MnFe})$. It should be noticed that $\mathrm{Si}$ was not detected by the mass spectrometric analysis, while EDS revealed a small amount of $\mathrm{Si}$ in correspondence of some intermetallic compounds. A possible explanation is that the $\mathrm{Si}$, present in a very low content, segregated in these secondary phases.

\subsection{Tensile and hardness data}

Vickers hardness measurements $\mathrm{HV}_{1}$ were performed on metallographic samples and, by referring to Fig. 4, they were conducted on the three main directions considered $(x-z, z-y$ and $x-y$ plane) to determine the overall hardness of samples. Hardness values in the range $79-84 \mathrm{HV}_{1}$ were measured in all the investigated samples, that can be considered comparable values when taking into account the standard deviations (Table 3 ). The resulting hardness is consistent and even higher than the values reported in literature for similar alloys processed by WAAM [19, 20]. The measured hardness is higher than nominal value reported for conventional AA5083-O sheets, equal to $75 \mathrm{HB}$ that can be conventionally compared to $75 \mathrm{HV}$ [25]. Following the Hall-Petch relationship, the increase in hardness is mainly due to the very fine microstructure resulting from WAAM process.

Figure 11 shows the whole engineering stress-strain curves for specimens L (Fig. 11a), T (Fig. 11b) and D (Fig. 11c). The curves showed in general a quite uniform stress-strain behavior within each specimen orientation, also evidenced in the low standard deviations presented in Table 4. All directions presented a first elastic branch, followed by a post-yielding hardening behavior. Specimen $1 \mathrm{D}$ did not reach full rupture but only partial, but given that the trend registered was in line with the other
Table 3 Hardness measurements carried out on samples: mean values and standard deviations

\begin{tabular}{ll}
\hline Samples & $\mathrm{HV}_{1}$ \\
\hline $\mathrm{L}$ & $84 \pm 4$ \\
$\mathrm{D}$ & $81 \pm 3$ \\
$\mathrm{~T}$ & $79 \pm 4$ \\
\hline
\end{tabular}




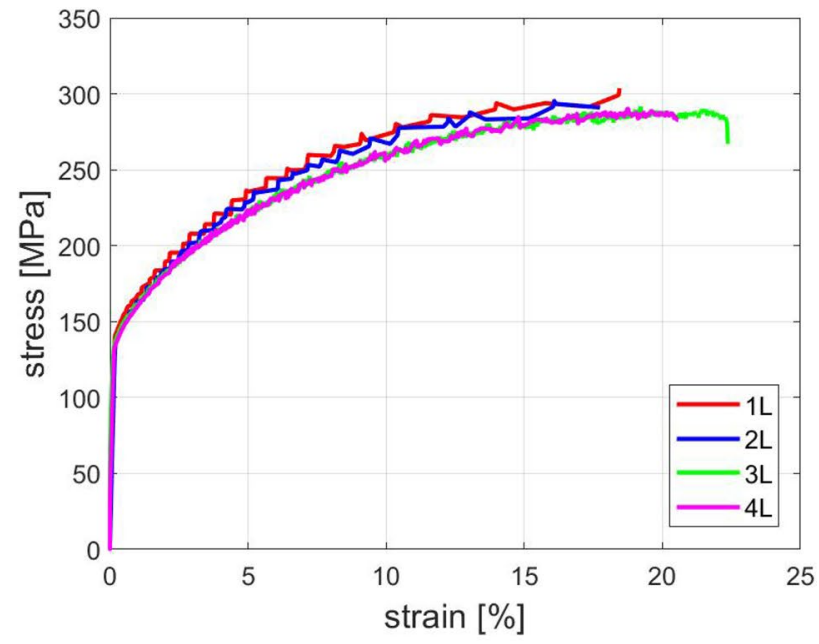

a

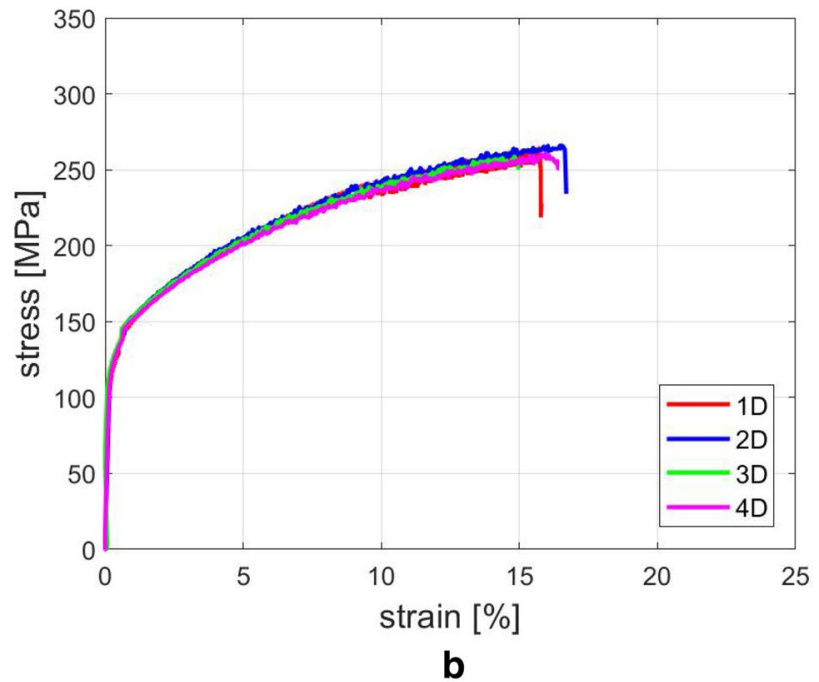

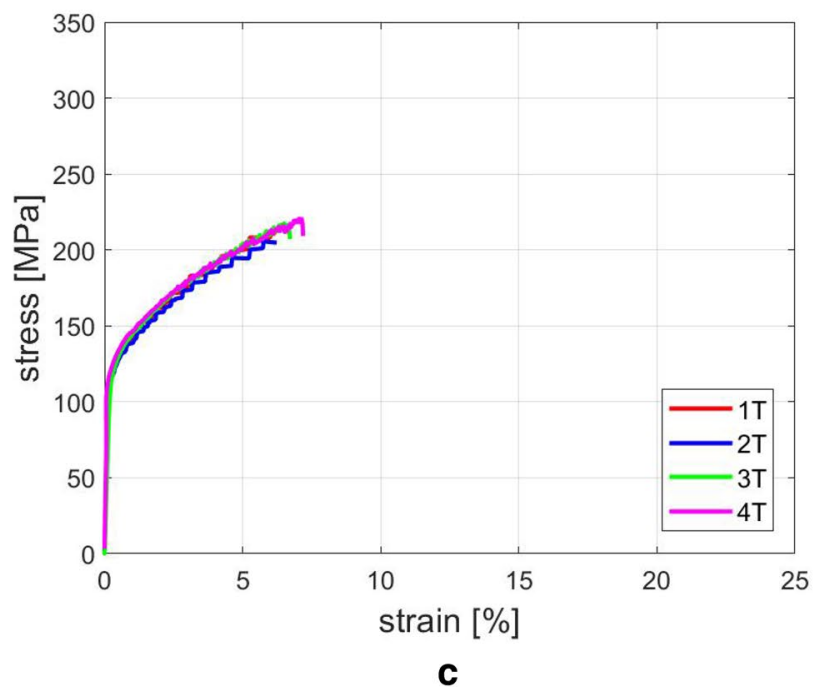

Fig. 11 Stress-strain curves for tensile tests: a longitudinal (L); b diagonal D; $\mathbf{c}$ transversal (T) specimens

tests carried out on specimens with the same orientation, it has been taken under consideration as well. Therefore, it should be noted that for this specimen, the values of UTS and $A_{\%}$ have been taken at the failure point corresponding to its partial rupture. It is worth noticing that all three orientations evidenced the phenomenon of serrated yielding or serrated flow, also known as the Portevin-Le Chatelier (PLC) effect, as reported also by [20] for the same WAAM processed AA5083 alloy. This phenomenon is due to plastic deformation instability and can be observed in the stress-strain curves of many metal alloys as repetitive steps, called yielding teeth or serrated yielding [56]. The PLC effect is associated with diffusion of solute atoms occurring at higher rate than speeds of dislocations and is a well-known issue concerning $\mathrm{Al}-\mathrm{Mg}$ alloys as well as the 5083 alloy [56-58], but it has also been associated with preferential crystallographic orientations [59].
This suggests that the serrated yielding observed in the stress-strain curves of the WAAM specimens is an intrinsic property of the specific alloy but can be also related to the additive process.

The main tensile properties in terms of Young's modulus $(E)$, yield stress (YS), ultimate tensile strength (UTS), elongation to failure $\left(A_{\%}\right)$ and strength ratio (YS/UTS) are reported in Table 4, for the three specimen orientations. As far as the influence of orientation is concerned, specimens oriented longitudinally (L) presented the highest values of ultimate tensile strength, up to $300 \mathrm{MPa}$; whereas, those oriented transversally $(\mathrm{T})$ presented the lowest values, of around $200 \mathrm{MPa}$. These latter ones also showed the lowest values of elongation to failure, of about $7 \%$, which is less than half of the average value for both orientations $L$ and $D$. Young's modulus values ranged from 66 to $86 \mathrm{GPa}$, being the lowest for specimens D and the highest for specimens 
Table 4 Summary of tensile tests results (in bold: mean values and standard deviations)

\begin{tabular}{llllll}
\hline $\begin{array}{l}\text { Specimen } \\
\text { ID }\end{array}$ & E (GPa) & YS (MPa) & UTS $(\mathrm{MPa})$ & $\mathrm{A}_{\%}(\%)$ & YS/UTS \\
\hline 1-L & 86 & 144 & 304 & 18 & 0.47 \\
2-L & 75 & 143 & 295 & 17 & 0.48 \\
3-L & 88 & 145 & 292 & 22 & 0.50 \\
4-L & 71 & 141 & 290 & 21 & 0.49 \\
$\boldsymbol{\mu}$ & $\mathbf{8 0} \pm \mathbf{8}$ & $\mathbf{1 4 3} \pm \mathbf{1}$ & $\mathbf{2 9 5} \pm \mathbf{5}$ & $\mathbf{2 0} \pm \mathbf{2}$ & $\mathbf{0 . 4 8} \pm \mathbf{0 . 0 1}$ \\
1-D & 64 & 115 & 265 & 16 & 0.43 \\
2-D & 66 & 131 & 266 & 17 & 0.49 \\
3-D & 66 & 132 & 259 & 15 & 0.51 \\
4-D & 68 & 129 & 261 & 16 & 0.50 \\
$\boldsymbol{\mu}$ & $\mathbf{6 6} \pm \mathbf{1}$ & $\mathbf{1 2 7} \pm \mathbf{7}$ & $\mathbf{2 6 3} \pm \mathbf{3}$ & $\mathbf{1 6} \pm \mathbf{1}$ & $\mathbf{0 . 4 8} \pm \mathbf{0 . 0 3}$ \\
1-T & 93 & 125 & 218 & 6 & 0.57 \\
2-T & 82 & 119 & 206 & 6 & 0.58 \\
3-T & 63 & 121 & 217 & 7 & 0.56 \\
4-T & 105 & 127 & 221 & 9 & 0.57 \\
$\boldsymbol{\mu}$ & $\mathbf{8 6} \pm \mathbf{1 5}$ & $\mathbf{1 2 3} \pm \mathbf{3}$ & $\mathbf{2 1 5} \pm \mathbf{6}$ & $\mathbf{7} \pm \mathbf{1}$ & $\mathbf{0 . 5 7} \pm \mathbf{0 . 0 1}$ \\
\hline
\end{tabular}

Table 5 Comparison of tensile tests results

\begin{tabular}{lllll}
\hline & E $(\%)$ & YS $(\%)$ & UTS $(\%)$ & $\mathrm{A}_{\%}(\%)$ \\
\hline$(\mathrm{D}-\mathrm{L}) / \mathrm{L}$ & -18 & -14 & -11 & -18 \\
$(\mathrm{~T}-\mathrm{L}) / \mathrm{L}$ & +7 & -15 & -27 & -64 \\
$(\mathrm{~T}-\mathrm{D}) / \mathrm{D}$ & +31 & -1 & -18 & -56 \\
\hline
\end{tabular}

T. Values of strength ratio (YS/UTS) ranged from 0.48 (for both $\mathrm{L}$ and $\mathrm{D}$ ) to 0.57 (for T), further evidencing the influence of orientation on tensile strength values.

The values of the mechanical properties reported in Table 4 indicated overall a quite anisotropic behavior of WAAM aluminum alloy specimens, further confirmed in the ratios presented in Table 5. In fact, the anisotropic trend for yield stress, ultimate tensile strength and elongation to failure is evidenced by the relative differences among the three tested directions. Specifically, T specimens showed the lowest values, with a drop of approximately $27 \%$ in the ultimate strength and $64 \%$ in the elongation by comparison to $\mathrm{L}$ specimens, and 18 and $56 \%$, respectively, if compared with $\mathrm{D}$ specimens. The mechanical behavior on $\mathrm{T}$ directions was further investigated by analyzing fracture surfaces and, as will be later discussed, was strongly related to the microstructural defects.

The bar charts of Fig. 12 provide a graphical comparison of the three different orientations tested for each investigated tensile property. In particular, the trends showed a marked anisotropic behavior mainly for both ultimate tensile strength and elongation to failure values (Fig. 12c, d), for which in both cases, the highest value is for orientation $\mathrm{L}$ and the lowest for T. A similar trend can be observed for yield stress (Fig. 12b), although the difference among the three orientations is slightly lower. Young's modulus values presented instead a different trend, since specimens $\mathrm{L}$ and $\mathrm{T}$ exhibited similar values while specimens D showed the lowest one. However, by taking into account the high standard deviations registered for specimens $\mathrm{D}$ and $\mathrm{L}$, the values can be considered almost comparable for all directions.

The different mechanical response of the three orientations will be explained when analyzing the results of fracture surfaces characterization, reported in the next section.

A summary of results found in the literature for the additively manufactured aluminum alloys of the 5000 series is presented in Table 6, including reference values from ASM Handbook [25]. It is worth noticing that only $\mathrm{L}$ and $\mathrm{T}$ specimens were generally considered in the literature, while no data are reported on specimens $\mathrm{D}$, with $45^{\circ}$ orientation to the deposition layer.

By comparing the results of the present study with the outcomes of previous experiments on similar WAAM processed aluminum alloys, it can be noticed that in general yield stress and ultimate tensile strength values are in line with the results of the present work. However, greater values of elongation to failure for specimens $\mathrm{T}$ were presented in literature than values obtained in the present campaign. It is worth mentioning that only one reference [20] declared values of Young's modulus, and for L specimens only, which resulted on average in line with the experimental results reported in the present study.

It is worth noting that the values of tensile strength and elongation measured on $\mathrm{L}$ specimens were higher than those reported for the conventionally manufactured thin $(1.2-6.3 \mathrm{~mm})$ sheets of the $5083-\mathrm{O}$ alloy. D specimens exhibited values on average in line or slightly lower than the standard requirements. On the other hand, T specimens differed from the values of the standard alloy especially with regard to the ultimate tensile strength (215 MPa vs $275 \mathrm{MPa}$ ) and elongation to failure ( $7 \%$ vs $16 \%$ ).

\subsection{Fracture surfaces}

To study the main fracture mechanisms occurred during tensile tests, fracture area have been investigated both at low and high magnification. Low magnification analyses of the lateral view of the fracture area (Fig. 13a-c) suggested that, in case of $\mathrm{D}$ and $\mathrm{T}$ samples, fracture occurred along a boundary layer; while in case of $\mathrm{L}$ samples, fracture crossed over the layers. The same was confirmed by metallographic analyses carried out on polished sections of fracture surfaces, where it can be clearly seen that fracture path followed the boundary between two consecutive layers for samples D and $\mathrm{T}$. The behavior can be explained by referring to microstructural analyses (Sect. 3.3), that revealed defects, such as 


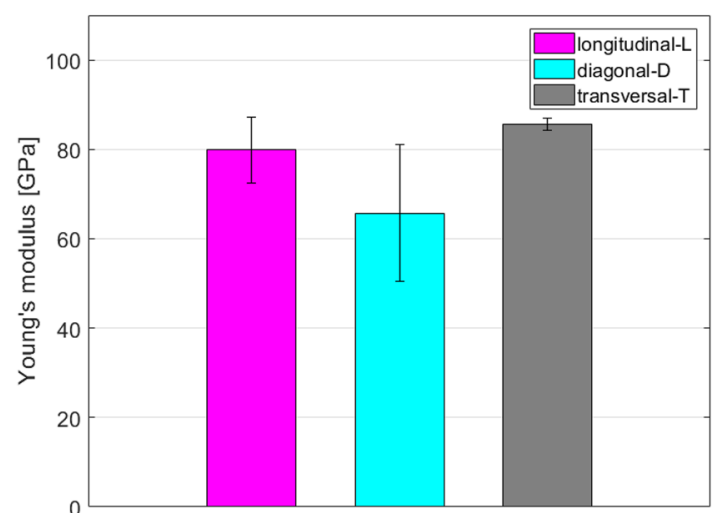

a

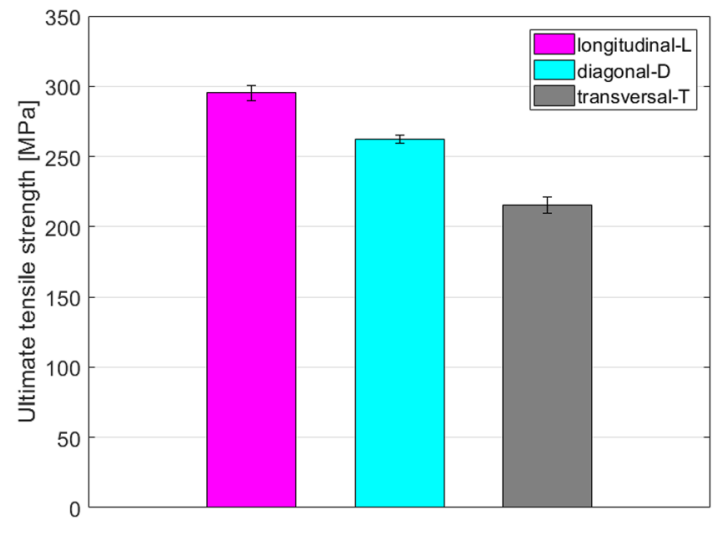

C

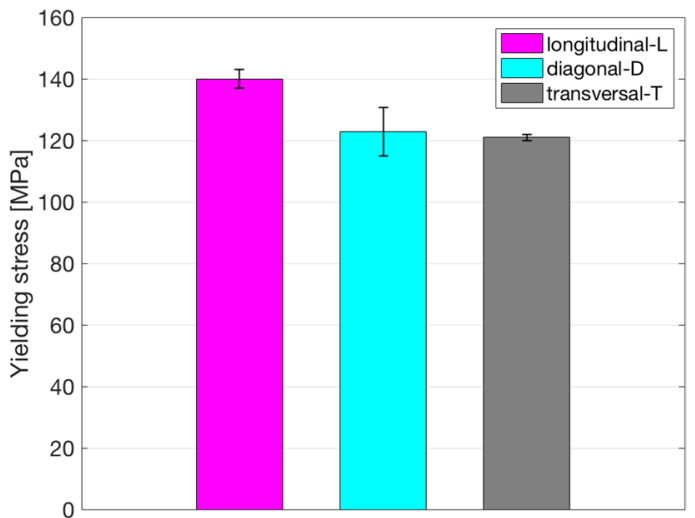

b

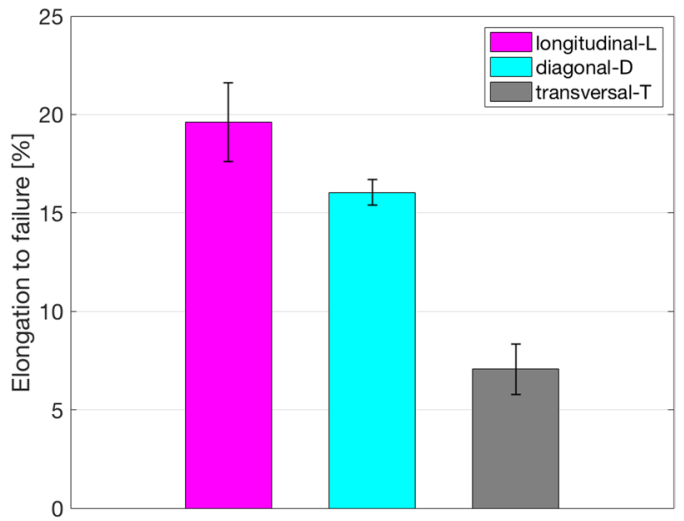

d

Fig. 12 Results of the tensile tests on longitudinal (L), diagonal (D) and transversal (T) specimens cut from WAAM plates according to the scheme in Fig. 1: a Young's modulus; b yield stress; $\mathbf{c}$ ultimate tensile strength; $\mathbf{d}$ elongation to failure

Table 6 Overview of tensile properties of WAAM-produced aluminum alloys of the 5000 series from literature review

\begin{tabular}{|c|c|c|c|c|c|c|c|}
\hline & Alloy & $\begin{array}{l}\text { Specimen } \\
\text { orientation }\end{array}$ & $\mathrm{E}(\mathrm{GPa})$ & YS (MPa) & UTS (MPa) & $\mathrm{A}_{\%}(\%)$ & References \\
\hline \multicolumn{8}{|l|}{ Present study } \\
\hline \multirow[t]{3}{*}{ WAAM } & 5183 & $\mathrm{~L}$ & 80 & 143 & 295 & 20 & I \\
\hline & & $\mathrm{D}$ & 66 & 123 & 263 & 16 & \\
\hline & & $\mathrm{T}$ & 86 & 122 & 215 & 7 & \\
\hline \multicolumn{8}{|c|}{ Literature review } \\
\hline \multirow[t]{10}{*}{ WAAM } & 5356 & $\mathrm{~L}$ & I & 115 & 268 & 28 & {$[31]$} \\
\hline & & $\mathrm{T}$ & / & 115 & 254 & 17 & \\
\hline & 5183 & $\mathrm{~L}$ & 73 & 145 & 293 & l & [20] \\
\hline & 5183 & $\mathrm{~L}$ & / & I & 293 & l & [18] \\
\hline & & $\mathrm{T}$ & I & I & 281 & l & \\
\hline & 5087 & $\mathrm{~L}$ & I & 142 & 291 & 22.4 & [19] \\
\hline & $\mathrm{A} 15-3.1 \mathrm{Mg}-2.0 \mathrm{Si}$ & $\mathrm{L}$ & / & 77 & 176 & 11 & [26] \\
\hline & & $\mathrm{T}$ & I & 77 & 170 & 11 & \\
\hline & Al-Mg6 & $\mathrm{L}$ & I & / & 315 & I & {$[21]$} \\
\hline & & $\mathrm{T}$ & I & I & 265 & l & \\
\hline \multicolumn{8}{|c|}{ Reference values } \\
\hline $\begin{array}{l}\text { Sheet } \\
\text { (thickness } \\
\quad 1.2-6.3 \mathrm{~mm} \text { ) }\end{array}$ & $5083-\mathrm{O}$ & l & 70 & 125 & 275 & 16 & {$[25]$} \\
\hline
\end{tabular}




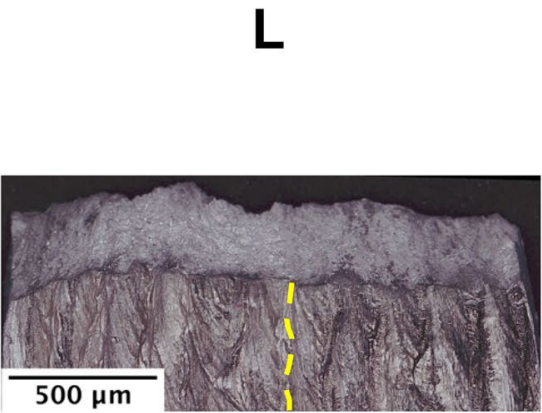

a

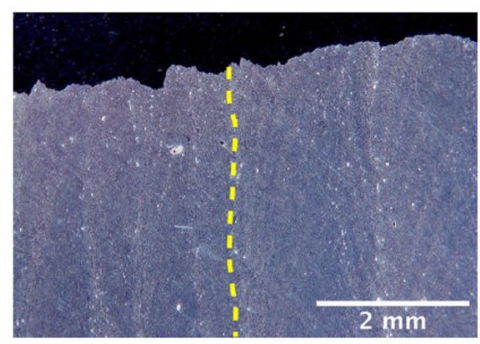

d
D

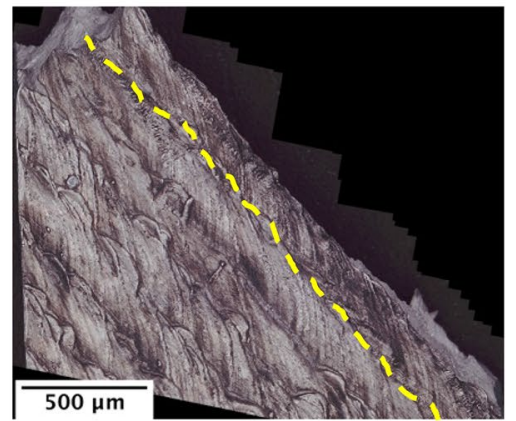

b

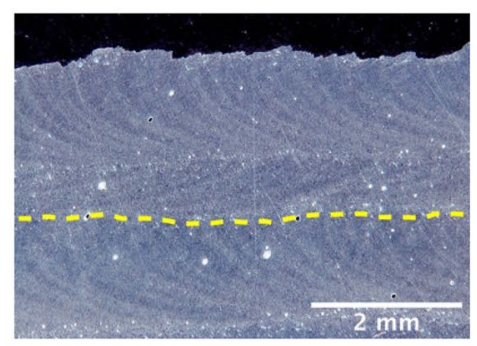

e

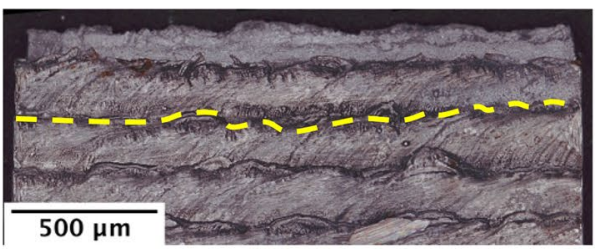

C

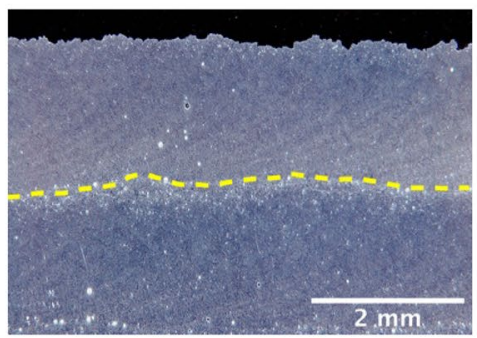

f

Fig. 13 3D digital analyses of fracture region $(x-z$ plane): a-c lateral view for sample L, D and T, respectively; $\mathbf{d}-\mathbf{f}$ corresponding metallographic cross sections. Deposition layers are defined by yellow dashed lines

porosities and cracks, mainly located in correspondence of interlayer regions.

This result was confirmed also by low magnification FEG-SEM investigation (Fig. 14a-c), that evidenced an extensive porosity on fracture surfaces, especially in case of samples $\mathrm{T}$ where pores strongly prevailed. The shape of pores on $\mathrm{L}$ and $\mathrm{T}$ surfaces was almost spherical (Fig. 14d, f); while on D surfaces, it was quite elongated (Fig. 14e). The dimensions of these defects in some case reached $100 \mu \mathrm{m}$, but for the most part, they lied in the size range 10-50 $\mu \mathrm{m}$. During tensile tests, and more in general when a load is applied, microcracks can generate from pores and eventually result in macrocracks, thus reducing the overall mechanical strength of the material [18]. So, if defects are unfavorably aligned with regard to the direction of the applied load, i.e., perpendicularly to the tensile load as for samples $\mathrm{T}$, they can be detrimental for the mechanical strength of the component. With reference to the mechanical tests results (Fig. 12), samples $\mathrm{T}$ showed indeed the lowest mechanical properties, in particular in terms of ultimate strength and elongation, while $\mathrm{L}$ ones the highest one. Thus, it could be inferred that the orientation of the deposition layer, that determined also the orientation of defects (pores and cracks), in regard to the tensile direction (Fig. 8), played an important role in determining the mechanical response of WAAM aluminum parts. Based on these results, in accordance with the outcomes reported in literature (Table 6), it is preferable to align the deposition layer with the tensile direction, as for sample L. Mechanical properties of $\mathrm{D}$ samples ranged in between those of $\mathrm{L}$ and $\mathrm{T}$ ones, so this suggests that orienting the layer at $45^{\circ}$ to the tensile direction is preferable than $90^{\circ}$.

Observation at higher magnification of the fracture surfaces evidenced the presence of dimples in all tested samples, typical of a ductile fracture (Fig. 15). Dimples were very fine (lower than $10 \mu \mathrm{m}$ ) and equiaxed on samples $\mathrm{L}$ (Fig. 15a), coarser but still equiaxed on T samples (Fig. 15b), while slightly elongated on D samples, due to the effect of shear stresses (Fig. 15c). As highlighted in Fig. 15d, e, very small particles (about $1 \mu \mathrm{m}$ ) were found inside dimples. EDS analyses revealed, by comparison with the aluminum matrix, an enrichment of $\mathrm{Mg}$ and $\mathrm{Fe}$, respectively, consistent with the intermetallic compounds evidenced by microstructural characterization (Sect. 3.3).

\section{Conclusions}

In the present work, the assessment of morphological, mechanical and microstructural features of aluminum plates produced by wire-and-arc additive manufacturing (WAAM) using an ER5183 wire was carried out. Aiming to a comprehensive characterization of the WAAM plates, all the analyses were performed on specimens extracted along the parallel (L), diagonal (D) and perpendicular (T) 


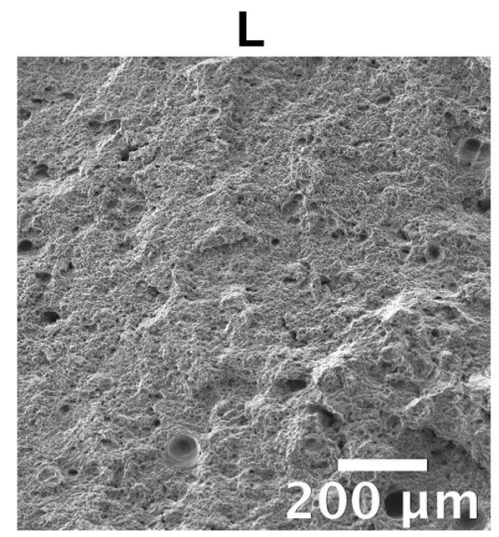

a

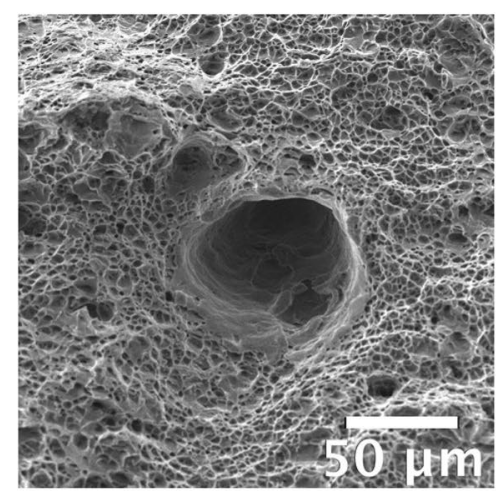

d

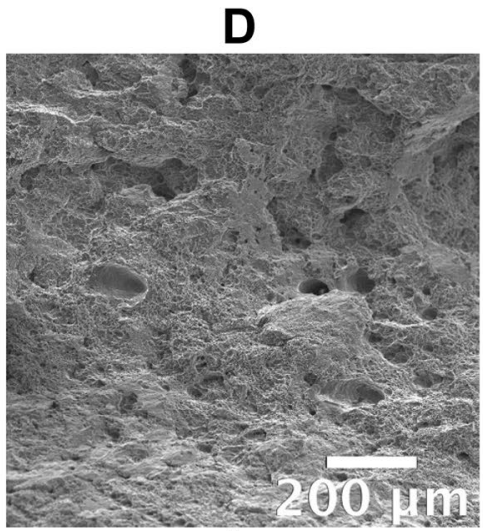

b

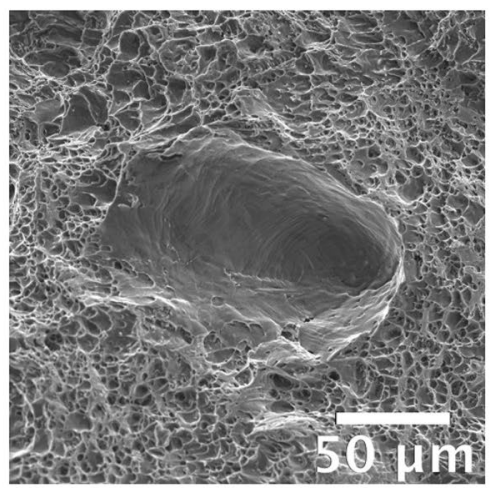

e

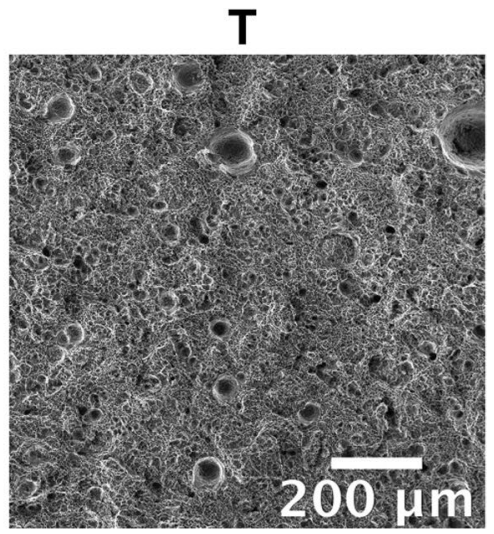

C

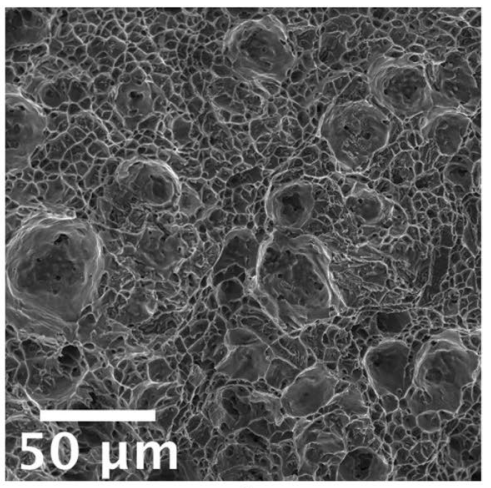

f

Fig. 14 FEG-SEM analyses of fracture surfaces ( $x-y$ plane): a-c low magnification micrographs for samples L, D and T; $\mathbf{d}-\mathbf{f}$ corresponding high magnification details of surfaces

direction, in regard to the deposition layer. Based on the experimental results, the following conclusions can be drawn:

- Chemical composition of WAAM plates complied with the standards for AA5183.

- The deposition process resulted in a layered structure comprised of successive solidified melt pools and the final microstructure of WAAM plates was composed by $\alpha$-Al phase and fine Fe- and Mg-based intermetallic particles homogeneously distributed in the aluminum matrix.

- Microstructural discontinuities (gas porosity and microcracks) were evidenced by microstructural analyses, especially located in the interlayer regions of all specimens. A consistent porosity was also evidenced on all fracture surfaces and, reasonably, it was the main responsible for the tensile behavior of the WAAM specimens.

- Results of tensile tests evidenced an anisotropic behavior, according to L, D and T orientation. L direction exhibited the highest tensile properties, overcoming values of conventional AA5083-O sheets. Similar values of the conventional alloy were registered for $\mathrm{D}$ direction. T direction, instead, was characterized by the lowest mechanical properties.

- The anisotropic tensile behavior was related to the alignment of the deposition layer in relation to the tensile direction, taking into account that microstructural discontinuities were mainly found in the interlayer area. Indeed, specimens $\mathrm{T}$, whose layers are perpendicular to the loading direction, exhibited the lowest mechanical properties while L specimens, whose layers are parallel, the highest ones. 


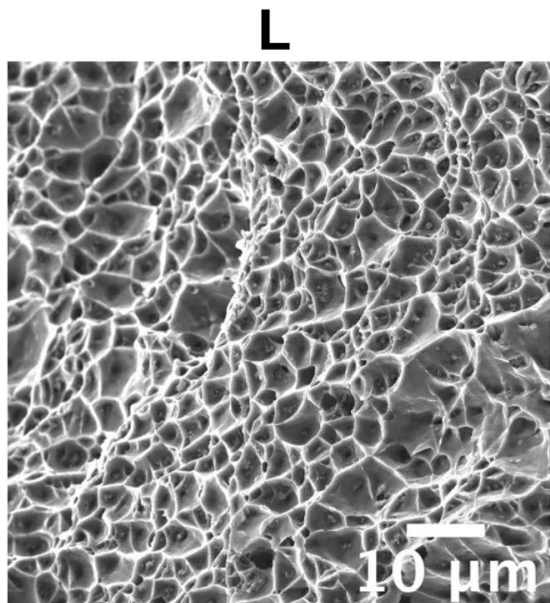

a

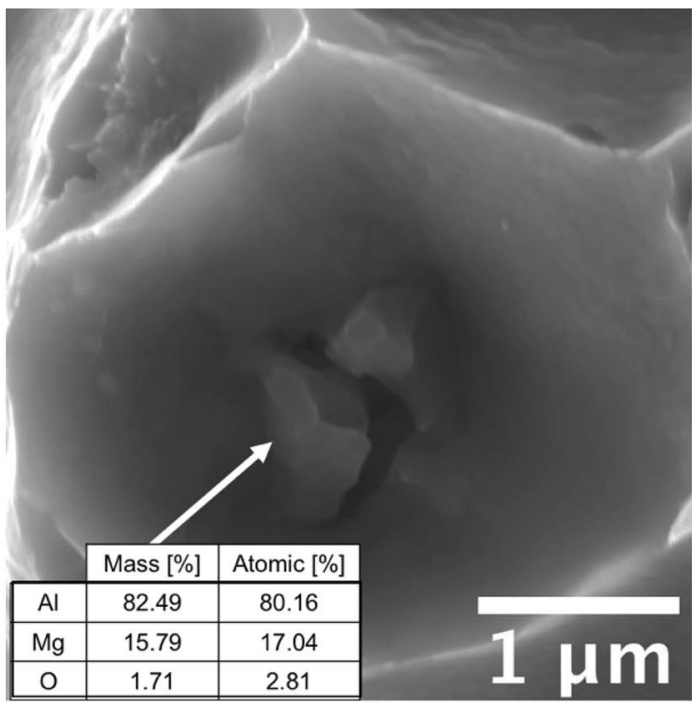

d

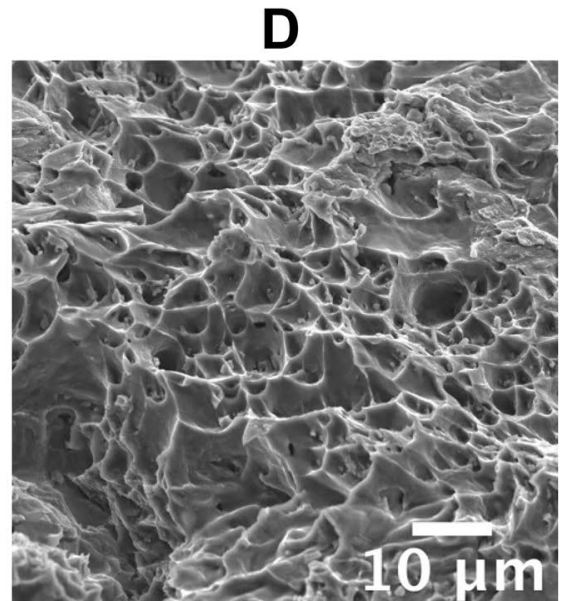

b

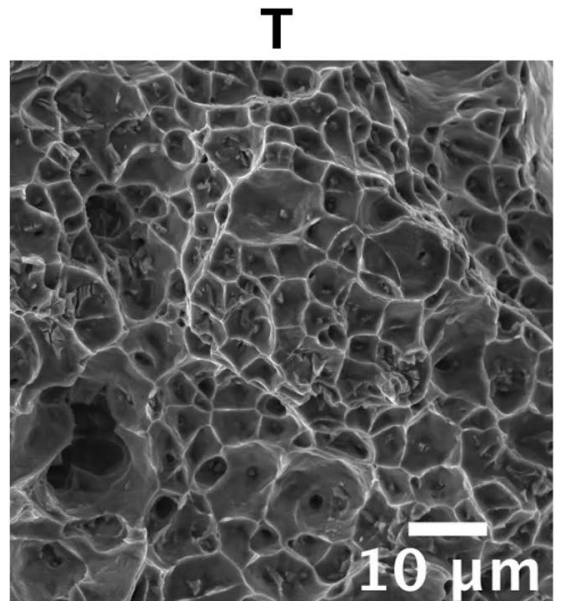

C

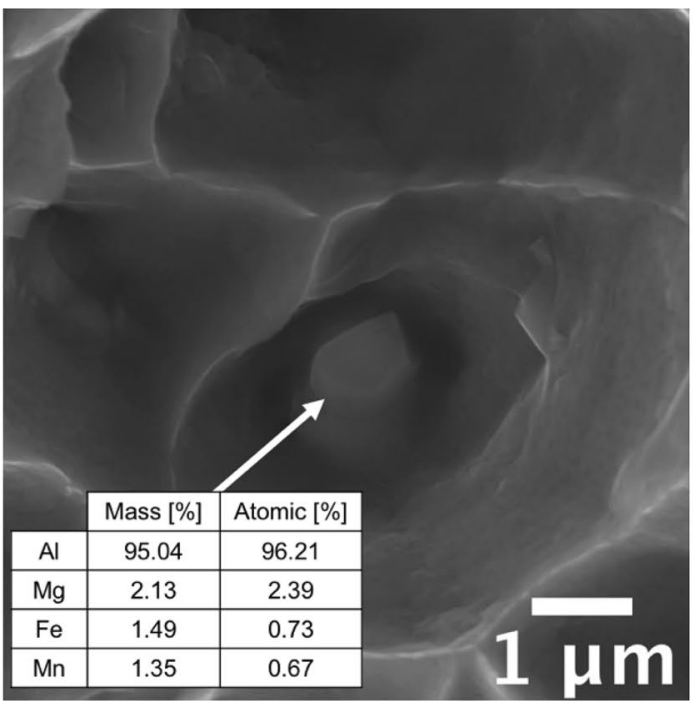

e

Fig. 15 High magnification FEG-SEM analyses of fracture surfaces: a-c dimples morphology for samples L, D and T; d, e semiquantitative FEG-SEM EDS analyses of particles inside of dimples

Acknowledgements The authors would like to thank Dr. Iuri Boromei at the University of Bologna for his valuable support in XRD and FEG-SEM analyses. The support of Dutch company MX3D held in Amsterdam is also gratefully acknowledged for giving the additivelymanufactured elements tested.

Funding Open access funding provided by Alma Mater Studiorum - Università di Bologna within the CRUI-CARE Agreement. This research did not receive any specific grant from funding agencies in the public, commercial, or not-for-profit sectors.

Code availability Not applicable.

\section{Declarations}

Conflict of interest The authors declare that they have no competing interest.
Availability of data and material Data supporting the findings of this study are available from the corresponding author, [L. T.], upon reasonable request.

Open Access This article is licensed under a Creative Commons Attribution 4.0 International License, which permits use, sharing, adaptation, distribution and reproduction in any medium or format, as long as you give appropriate credit to the original author(s) and the source, provide a link to the Creative Commons licence, and indicate if changes were made. The images or other third party material in this article are included in the article's Creative Commons licence, unless indicated otherwise in a credit line to the material. If material is not included in the article's Creative Commons licence and your intended use is not permitted by statutory regulation or exceeds the permitted use, you will need to obtain permission directly from the copyright holder. To view a copy of this licence, visit http://creativecommons.org/licenses/by/4.0/. 


\section{References}

1. Buchanan C, Gardner L (2019) Metal 3D printing in construction: a review of methods, research, applications, opportunities and challenges. Eng Struct 180:332-348. https://doi.org/10.1016/j. engstruct.2018.11.045

2. Wu B, Pan Z, Ding D, Cuiuri D, Li H, Xu J, Norrish J (2018) A review of the wire arc additive manufacturing of metals: properties, defects and quality improvement. J Manuf Process. https:// doi.org/10.1016/j.jmapro.2018.08.001

3. Wong KV, Hernandez A (2012) A review of additive manufacturing. ISRN Mech Eng 2012:1-10. https://doi.org/10.5402/ 2012/208760

4. Williams SW, Martina F, Addison AC, Ding J, Pardal G, Colegrove $\mathrm{P}$ (2016) Wire + arc additive manufacturing. Mater Sci Technol (UK) 32:641-647. https://doi.org/10.1179/17432 84715Y.0000000073

5. Uziel A (2016) Looking at large-scale, arc-based additive manufacturing. Weld J 4:42-46

6. Rodrigues TA, Duarte VR, Tomás D, Avila JA, Escobar JD, Rossinyol E, Schell N, Santos TG, Oliveira JP (2020) In-situ strengthening of a high strength low alloy steel during Wire and Arc Additive Manufacturing (WAAM). Addit Manuf 34:101200. https://doi.org/10.1016/j.addma.2020.101200

7. Duarte VR, Rodrigues TA, Schell N, Miranda RM, Oliveira JP, Santos TG (2020) Hot forging wire and arc additive manufacturing (HF-WAAM). Addit Manuf 35:101193. https://doi.org/10. 1016/j.addma.2020.101193

8. Jin W, Zhang C, Jin S, Tian Y, Wellmann D, Liu W (2020) Wire arc additive manufacturing of stainless steels: a review. Appl Sci. https://doi.org/10.3390/app10051563

9. Davis AE, Hönnige JR, Martina F, Prangnell PB (2020) Quantification of strain fields and grain refinement in Ti-6Al-4V interpass rolled wire-arc AM by EBSD misorientation analysis. Mater Charact 170:110673. https://doi.org/10.1016/j.matchar.2020. 110673

10. Xue L, Xiao J, Nie Z, Hao F, Chen R, Liu C, Yu X, Tan C (2021) Dynamic response of Ti-6.5Al-1Mo-1V-2Zr-0.1B alloy fabricated by wire arc additive manufacturing. Mater Sci Eng A 800:140310. https://doi.org/10.1016/j.msea.2020.140310

11. Resnina N, Palani IA, Belyaev S, Prabu SSM, Liulchak P, Karaseva U, Manikandan M, Jayachandran S, Bryukhanova V, Sahu A, Bikbaev R (2021) Structure, martensitic transformations and mechanical behaviour of NiTi shape memory alloy produced by wire arc additive manufacturing. J Alloys Compd 851:156851. https://doi.org/10.1016/j.jallcom.2020.156851

12. Zeng Z, Cong BQ, Oliveira JP, Ke WC, Schell N, Peng B, Qi ZW, Ge FG, Zhang W, Ao SS (2020) Wire and arc additive manufacturing of a Ni-rich NiTi shape memory alloy: Microstructure and mechanical properties. Addit Manuf 32:101051. https://doi.org/ 10.1016/j.addma.2020.101051

13. Wang J, Pan Z, Carpenter K, Han J, Wang Z, Li H (2021) Comparative study on crystallographic orientation, precipitation, phase transformation and mechanical response of Ni-rich $\mathrm{NiTi}$ alloy fabricated by WAAM at elevated substrate heating temperatures. Mater Sci Eng A 800:140307. https://doi.org/10.1016/j.msea. 2020.140307

14. Casati R, Nasab MH, Coduri M, Tirelli V, Vedani M (2018) Effects of platform pre-heating and thermal-treatment strategies on properties of AlSi10Mg alloy processed by selective laser melting. Metals (Basel) 8:954. https://doi.org/10.3390/met8110954

15. Tonelli L, Liverani E, Valli G, Fortunato A, Ceschini L (2020) Effects of powders and process parameters on density and hardness of A357 aluminum alloy fabricated by selective laser melting.
Int J Adv Manuf Technol 106:371-383. https://doi.org/10.1007/ s00170-019-04641-x

16. Marola S, Manfredi D, Fiore G, Poletti MG, Lombardi M, Fino P, Battezzati L (2018) A comparison of Selective Laser Melting with bulk rapid solidification of AlSi10Mg alloy. J Alloys Compd 742:271-279. https://doi.org/10.1016/j.jallcom.2018.01.309

17. Derekar KS (2018) A review of wire arc additive manufacturing and advances in wire arc additive manufacturing of aluminium. Mater Sci Technol (UK) 34:895-916. https://doi.org/10.1080/ 02670836.2018 .1455012

18. Fang X, Zhang L, Chen G, Dang X, Huang K, Wang L, Lu B (2018) Correlations between microstructure characteristics and mechanical properties in 5183 aluminium alloy fabricated by wire-arc additive manufacturing with different arc modes. Materials (Basel). https://doi.org/10.3390/ma11112075

19. Gu J, Wang X, Bai J, Ding J, Williams S, Zhai Y, Liu K (2018) Deformation microstructures and strengthening mechanisms for the wire + arc additively manufactured $\mathrm{Al}-\mathrm{Mg} 4.5 \mathrm{Mn}$ alloy with inter-layer rolling. Mater Sci Eng A 712:292-301. https://doi.org/ 10.1016/j.msea.2017.11.113

20. Horgar A, Fostervoll H, Nyhus B, Ren X, Eriksson M, Akselsen OM (2018) Additive manufacturing using WAAM with AA5183 wire. J Mater Process Technol. https://doi.org/10.1016/j.jmatp rotec.2018.04.014

21. Zhang C, Li Y, Gao M, Zeng X (2018) Wire arc additive manufacturing of Al-6Mg alloy using variable polarity cold metal transfer arc as power source. Mater Sci Eng A 711:415-423. https://doi. org/10.1016/j.msea.2017.11.084

22. Liang Z, Jinglong L, Yi L, Jingtao $\mathrm{H}$, Chengyang Z, Jie X, Dong C (2018) Characteristics of metal droplet transfer in wire-arc additive manufacturing of aluminum alloy. Int J Adv Manuf Technol 99:1521-1530. https://doi.org/10.1007/s00170-018-2604-7

23. Oyama K, Diplas S, M'hamdi M, Gunnæs AE, Azar AS (2019) Heat source management in wire-arc additive manufacturing process for Al-Mg and Al-Si alloys. Addit Manuf 26:180-192. https://doi.org/10.1016/j.addma.2019.01.007

24. Kosteas D (2016) Sustainability, durability and structural advantages as leverage in promoting aluminium structures. Key Eng Mater 710:13-21. https://doi.org/10.4028/www.scientific.net/ KEM.710.13

25. Anderson K, Weritz K, Kaufman JG (eds) (2019) ASM Handbook Volume 2B: Properties and selection of aluminum alloys. ASM International. https://doi.org/10.31399/asm.hb.v02b.9781627082 105

26. Qi Z, Qi B, Cong B, Zhang R (2018) ss. Mater Lett 233:348-350. https://doi.org/10.1016/j.matlet.2018.09.048

27. Thapliyal S (2019) Challenges associated with the wire arc additive manufacturing (WAAM) of aluminum alloys. Mater Res Express 6:112006. https://doi.org/10.1088/2053-1591/ab4dd4

28. Yuan T, Yu Z, Chen S, Xu M, Jiang X (2020) Loss of elemental $\mathrm{Mg}$ during wire + arc additive manufacturing of Al-Mg alloy and its effect on mechanical properties. J Manuf Process 49:456-462. https://doi.org/10.1016/j.jmapro.2019.10.033

29. Klein T, Schnall M (2020) Control of macro-/microstructure and mechanical properties of a wire-arc additive manufactured aluminum alloy. Int J Adv Manuf Technol 108:235-244. https://doi. org/10.1007/s00170-020-05396-6

30. Oliveira JP, Santos TG, Miranda RM (2020) Revisiting fundamental welding concepts to improve additive manufacturing: from theory to practice. Prog Mater Sci 107:100590. https://doi.org/10. 1016/j.pmatsci.2019.100590

31. Köhler M, Fiebig S, Hensel J, Dilger K (2019) Wire and arc additive manufacturing of aluminum components. Metals (Basel) 9:1-9. https://doi.org/10.3390/met9050608

32. Kyvelou P, Slack H, Mountanou DD, Wadee MA, Ben Britton T, Buchanan C, Gardner L (2020) Mechanical and microstructural 
testing of wire and arc additively manufactured sheet material. Mater Des. https://doi.org/10.1016/J.MATDES.2020.108675

33. Laghi V, Palermo M, Gasparini G, Girelli VA, Trombetti T (2021) On the influence of the geometrical irregularities in the mechanical response of Wire-and-Arc Additively Manufactured planar elements. J Constr Steel Res 178:106490. https://doi.org/10.1016/j. jcsr.2020.106490

34. Laghi V, Palermo M, Tonelli L, Gasparini G, Ceschini L, Trombetti T (2020) Tensile properties and microstructural features of 304L austenitic stainless steel produced by wire-and-arc additive manufacturing. Int J Adv Manuf Technol. https://doi.org/10.1007/ s00170-019-04868-8

35. Lopes JG, Machado CM, Duarte VR, Rodrigues TA, Santos TG, Oliveira JP (2020) Effect of milling parameters on HSLA steel parts produced by Wire and Arc Additive Manufacturing (WAAM). J Manuf Process 59:739-749

36. MX3D Webpage. http://www.mx3d.com. Accessed July 2020

37. AWS (1999) A5.10 specification for bare aluminum and aluminum-alloy welding electrodes and rods. American Welding Society

38. Oerlikon. https://www.oerlikon-welding.com/. Accessed July 2020

39. ISO 6892 (2019) Metallic materials - tensile testing. International Organization for Standardization

40. ASTM E8 (2010) ASTM E8/E8M standard test methods for tension testing of metallic materials 1. Annu Book ASTM Stand 4:1-27. https://doi.org/10.1520/E0008

41. European-Union (2007) Eurocode 9: design of aluminium structures-part 1-1: general structural rules. European Commettee for Standardization

42. EN ISO 4287 (2009) Geometrical product specifications (GPS) surface texture: profile method-terms, definitions and surface texture parameters. International Organization for Standardization

43. ASTM International (2017) E3 preparation of metallographic specimens. Annu Book ASTM Stand 11:1-17. https://doi.org/ 10.1520/E0003-11R17.1

44. Kou S (2003) Fluid flow and metal evaporation in welding. Welding metallurgy, 2nd edn. Wiley, Hoboken, pp 97-122

45. Rodrigues TA, Duarte V, Miranda RM, Santos TG, Oliveira JP (2019) Current status and perspectives on wire and arc additive manufacturing (WAAM). Materials (Basel). https://doi.org/10. 3390/ma12071121

46. Hatch JE (1984) Aluminum: properties and physical metallurgy. American Society for Metals, Metals Park, pp 58-104. https://doi. org/10.1361/apapm1984p00

47. Yasakau KA, Zheludkevich ML, Lamaka SV, Ferreira MGS (2007) Role of intermetallic phases in localized corrosion of AA5083. Electrochim Acta 52:7651-7659. https://doi.org/10. 1016/J.ELECTACTA.2006.12.072
48. Ran Q (2007) Aluminium-magnesium-manganese ternary alloy phase diagram. ASM Alloy Phase Diagram Center

49. Liu Y, Huang G, Sun Y, Zhang L, Huang Z, Wang J, Liu C (2016) Effect of $\mathrm{Mn}$ and $\mathrm{Fe}$ on the formation of $\mathrm{Fe}$ - and Mn-rich intermetallics in Al-5Mg-Mn alloys solidified under near-rapid cooling. Mater (Basel, Switzerland) 9:88. https://doi.org/10.3390/ma902 0088

50. Talbot DEJ (1975) Effects of hydrogen in aluminium, magnesium, copper, and their alloys. Int Metall Rev 20:166-184. https://doi. org/10.1179/imtlr.1975.20.1.166

51. Lippold JC, Nippes EF, Savage WF (1977) Investigation of hot cracking in 5083-0 aluminum alloy weldments. Weld Resear Suppl 6:171-178

52. Liu R, Dong Z, Pan Y (2006) Solidification crack susceptibility of aluminum alloy weld metals. Trans Nonferrous Met Soc China 16:110-116. https://doi.org/10.1016/S1003-6326(06)60019-8

53. Mousavi MG, Cross CE, Grong Ø (1999) Effect of scandium and titanium-boron on grain refinement and hot cracking of aluminium alloy 7108. Sci Technol Weld Join 4:381-388. https://doi.org/ $10.1179 / 136217199101538030$

54. Xu Z, Zhao Z, Wang G, Zhang C, Cui J (2014) Microstructure and mechanical properties of the welding joint filled with microalloying 5183 aluminum welding wires. Int J Miner Metall Mater 21:577-582. https://doi.org/10.1007/s12613-014-0944-3

55. DebRoy T, Wei HL, Zuback JS, Mukherjee T, Elmer JW, Milewski JO, Beese AM, Wilson-Heid A, De A, Zhang W (2018) Additive manufacturing of metallic components-process, structure and properties. Prog Mater Sci 92:112-224. https://doi.org/10.1016/j. pmatsci.2017.10.001

56. Trusov PV, Chechulina EA (2014) Serrated yielding: physical mechanisms, experimental dates, macrophenomenological models. PNRPU Mech Bull 2014:186-232. https://doi.org/10.15593/ perm.mech/2014.3.10

57. Yilmaz A (2011) The Portevin-Le Chatelier effect: a review of experimental findings. Sci Technol Adv Mater. https://doi.org/10. 1088/1468-6996/12/6/063001

58. Sheikh H (2010) Investigation into characteristics of Portevin-Le Chatelier effect of an Al-Mg alloy. J Mater Eng Perform 19:12641267. https://doi.org/10.1007/s11665-010-9634-0

59. Shen YZ, Oh KH, Lee DN (2004) The effect of texture on the Portevin-Le Chatelier effect in 2090 Al-Li alloy. Scr Mater 51:285-289. https://doi.org/10.1016/j.scriptamat.2004.04.030

Publisher's Note Springer Nature remains neutral with regard to jurisdictional claims in published maps and institutional affiliations. 